\title{
The Future of Family Medicine: A Collaborative Project of the Family Medicine Community
}

\author{
Future of Family Medicine Project Leadership Committee \\ James C. Martin, MD, Project Leadership Committee Chair, Family Practice Resi- \\ dency Program at CHRISTUS Santa Rosa Health Care, San Antonio, Tex. \\ Robert F. Avant, MD, American Board of Family Practice, Lexington, $\mathrm{Ky}_{\text {; }}$ Marjorie \\ A. Bowman, MD, MPA, Department of Family Practice and Community Medicine, \\ University of Pennsylvania Health System, Pbiladelpbia, Pa, Jobn R. Bucholtz, \\ DO, Columbus Family Practice Residency Program, Columbus, Ga, Jobn C. Dick- \\ inson, MD, Department of Family Medicine, University of Rochester School of Medi- \\ cine and Dentistry, Rochester, NY; Kenneth L. Evans, MD, Stillwater, Okla, Larry \\ A. Green, MD, Robert Grabam Center: Policy Studies in Family Practice \& Primary \\ Care, Washington, DC, Department of Family Medicine, University of Colorado, \\ Denver, Col, Douglas E. Henley, MD, American Academy of Family Physicians, \\ Leawood, Kan, Warren A. Jones, MD, State of Mississippi, Jackson, Miss; Samuel \\ C. Matheny, MD, MPH, Department of Family Practice and Community Medicine, \\ University of Kentucky, Lexington, Ky, Janice E. Nevin, MD, MPH, Department \\ of Family and Community Medicine, Christiana Care Health System, Wilmington, \\ Del; Sandra L. Panther, CFRE, American Academy of Family Pbysicians Founda- \\ tion, Leawood, Kan, James C. Puffer, MD, American Board of Family Practice, \\ Lexington, Ky, Richard G. Roberts, MD, JD, Department of Family Medicine, \\ University of Wisconsin, Madison, Wisc; Denise V. Rodgers, MD, Scbool of Com- \\ munity Health, Robert Wood Jobnson Medical School, New Brunswick, NJ, Roger \\ A. Sherwood, CAE, Society of Teachers of Family Medicine, Leawood, Kan; Kurt C. \\ Stange, $M D, P b D$, Department of Family Medicine, Case Western Reserve Univer- \\ sity, Cleveland, Obio; and Cyntbia W. Weber, MA, Association of Family Practice \\ Residency Program Directors, Leawood, Kan.*
}

FFM Executive Editorial Team: Thomas M. Gorey, JD, Policy Planning Associates, Inc, Crystal Lake, Ill, Norman B. Kabn, Jr, MD, American Academy of Family Pbysicians, Leawood, Kan; Sarab Thomas, American Academy of Family Physicians, Leawood, Kan, and Marilyn A. McMillen, MBA, American Academy of Family Physicians, Leawood, Kan.

*See Acknowledgments for a list of all the task force members whose work contributed to this report.

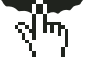

\section{MORE ONLINE}

Conflicts of interest: none reported

\section{CORRESPONDING AUTHOR}

Norman B. Kahn, Jr, MD

American Academy of Family Physicians

11400 Tomahawk Creek Parkway

Leawood, KS 66211-2672

nkahn@aafp.org

\begin{abstract}
BACKGROUND Recognizing fundamental flaws in the fragmented US health care systems and the potential of an integrative, generalist approach, the leadership of 7 national family medicine organizations initiated the Future of Family Medicine (FFM) project in 2002. The goal of the project was to develop a strategy to transform and renew the discipline of family medicine to meet the needs of patients in a changing health care environment.
\end{abstract}

METHODS A national research study was conducted by independent research firms. Interviews and focus groups identified key issues for diverse constituencies, including patients, payers, residents, students, family physicians, and other clinicians. Subsequently, interviews were conducted with nationally representative samples of 9 key constituencies. Based in part on these data, 5 task forces addressed key issues to meet the project goal. A Project Leadership Committee synthesized the task force reports into the report presented here.

RESULTS The project identified core values, a New Model of practice, and a process for development, research, education, partnership, and change with great potential to transform the ability of family medicine to improve the health and health care of the nation. The proposed New Model of practice has the following characteristics: a patient-centered team approach; elimination of barriers to access; advanced information systems, including an electronic health record; redesigned, more functional offices; a focus on quality and outcomes; and enhanced practice finance. A unified communications strategy will be developed to promote the New Model of family medicine to multiple audiences. The study concluded that the discipline needs to oversee the training of family physicians who are committed to excellence, steeped in the core values of the discipline, competent to provide family medicine's basket of services within the New Model, and capable of adapting to varying patient needs and changing care technologies. Family medicine education must continue to include training in maternity care, the care of hospitalized patients, community and population health, and culturally effective and proficient care. A comprehensive lifelong learning program for each family physician will support continuous personal, professional, and clinical practice assessment and improvement.

Ultimately, systemwide changes will be needed to ensure high-quality health care for all Americans. Such changes include taking steps to ensure that every American has a personal medical home, promoting the use and reporting 
of quality measures to improve performance and service, advocating that every American have health care coverage for basic services and protection against extraordinary health care costs, advancing research that supports the clinical decision making of family physicians and other primary care clinicians, and developing reimbursement models to sustain family medicine and primary care practices.

CONCLUSIONS The leadership of US family medicine organizations is committed to a transformative process. In partnership with others, this process has the potential to integrate health care to improve the health of all Americans.

Ann Fam Med 2004;2:S3-S32. DOI: 10.1370/afm.130.

\section{PREFACE}

$\mathrm{R}$ ecognizing growing frustration among family physicians, confusion among the public about the role of family physicians, and continuing inequities and inefficiencies in the US health care system, the leadership of 7 national family medicine organizations initiated the Future of Family Medicine (FFM) project in 2002. The goal of the project was to transform and renew the specialty of family medicine to meet the needs of people and society in a changing environment.

The work of the FFM project was overseen by the Project Leadership Committee, composed of representatives from the sponsoring organizations: the American Academy of Family Physicians, the American Academy of Family Physicians Foundation, the American Board of Family Practice, the Association of Departments of Family Medicine, the Association of Family Practice Residency Directors, the North American Primary Care Research Group, and the Society of Teachers of Family Medicine.

The project received financial support from the 7 family medicine organizations and from a combination of other supporters listed on page S30. The project was staffed by the American Academy of Family Physicians and organized to accomplish its charge through the work of 5 task forces. Task force members included individuals from diverse fields, drawing from a broad representation of health care professionals concerned with primary care, policy makers, and representatives of the patient voice. The task forces vetted and modified this work based on important input from reactor panels with diverse membership.

The 5 task forces and their charges were as follows:

Task Force 1: To consider the core attributes and values of family medicine and propose ideas about reforming family medicine and primary care to meet the contemporary needs and expectations of the people of the United States. The final report, "Task Force
Report 1. Report of the Task Force on Patient Expectations, Core Values, Re-Integration, and the New Model of Family Medicine," is available online at http:// www.annfammed.org/content/vol2/suppl_1/index.shtml.

Task Force 2: To determine the training needed for family physicians to deliver core attributes and system services. The final report, "Task Force Report 2. Report of the Task Force on Medical Education," is available online at http://www.annfammed.org/content/vol2/ suppl_1/index.shtml.

Task Force 3: To ensure that family physicians deliver core attributes and system services throughout their careers. The final report, "Task Force Report 3.

Report of the Task Force on Continuous Personal, Professional, and Practice Development in Family Medicine," is available online at http://www.annfammed.org/content/ vol2/suppl_1/index.shtml.

Task Force 4: To determine strategies for communicating the role of family physicians within medicine and health care, as well as to purchasers and consumers. The final report, "Task Force Report 4. Report of the Task Force on Marketing and Communications," is available online at http://www.annfammed.org/content/ vol2/suppl_1/index.shtml.

Task Force 5: To determine family medicine's leadership role in shaping the future health care delivery system. The final report, "Task Force Report 5. Report of the Task Force on Family Medicine's Role in Shaping the Future Health Care Delivery System," is available online at http://www.annfammed.org/content/vol2/ suppl_1/index.shtml.

One project recommendation-to develop reimbursement models that sustain and promote primary care practices-led to the formation of a sixth task force focused solely on enhancing practice reimbursement and finance issues. Task Force 6 is expected to report its findings and recommendations later in 2004.

A primary objective of the FFM project was to recommend changes to the discipline so that family medicine can better meet the health care needs of patients in a changing environment. Family physicians are relying on the FFM project to identify strategic directions that resonate across the discipline and with others seeking to improve health care and health. The report offers specific recommendations to help improve family physicians' performance.

At the same time, family medicine cannot fully succeed, nor will the needs of the public be met, without fundamental changes in the US health care system. Americans are frustrated by a health care system that produces wondrous results for a few, but costs so much that even basic care is increasingly unaffordable for many; that promises the latest in science and technology, but delivers care that is fragmented, impersonal, or 
of inconsistent quality; that permits experimentation in health plan provisions and financial incentives, but does not learn from the resulting chaos and inequities.

This report is an attempt to stimulate and guide some initial steps toward a serious revision of family medicine and health care in the United States. It should not be interpreted as an explicit blueprint, but rather as a compass and a call to action for family physicians and others concerned with the specialty; a call to exert leadership in implementing a compelling vision for a better family medicine, stronger primary care, and an improved US health care system. It was the intent of the FFM project to be bold enough to inspire, but sufficiently practical and incremental as to present achievable next steps in a journey that began long ago and seems destined to continue for as long as human beings feel the need to seek the help of a trusted healer.

As a key initial step in the development of this report, a national research study was conducted by independent research firms. This effort produced a wealth of interesting, and in some cases provocative, quantitative, and qualitative findings. The FFM research data will be maintained at the Robert Graham Center: Policy Studies in Family Practice and Primary Care in Washington DC, and will be made available for future study and research. Additional background information, including the original task force reports, will be maintained in the Center for the History of Family Medicine in Leawood, Kan. The professional organizations of family medicine are encouraged to review these data critically and to make this information widely available to their individual constituents as a starting point for building consensus on the need to implement the recommendations of the FFM project.

This report reflects a vision of the role of the discipline of family medicine in the US health care system. The Project Leadership Committee sought outside research and external opinions, individually and in many public forums, and they specifically included persons outside the discipline of family medicine. Yet, the report reflects the experience, skills, strengths, and weaknesses of the individuals involved, including their interpretation of the invited input and available data. Nevertheless, the Project Leadership Committee believed the urgency of the situation required deriving conclusions and recommendations with current information.

It is an enormous task to retool the specialty and reform the health care system. The results of this project are highly dependent on the ensuing input, critique, and implementation by family physicians throughout the country, individuals within the public, policy makers, other health care professionals, and patients themselves. The Project Leadership Committee strongly desires further reflection and energetic discussion of both the con- clusions and the recommendations. These ideas need to be tested and refined in practice. Of particular interest will be the response and assistance of those to be served by the New Model of family medicine.

\section{INTRODUCTION}

Nearly 4 decades ago, the specialty of family practice was created to fulfill the generalist function in medicine, which the American people wanted and which suffered with the growth of subspecialization after World War II. Although the specialty has delivered on its promise to reverse the decline of general practice ${ }^{1,2}$ and provide personal, frontline medical care to people of all socioeconomic strata and in all regions of the United States, ${ }^{3}$ all is not well either with family medicine or with health care in general. ${ }^{4-11}$

At the national level, serious health policy issues appear to be intractable. A large proportion of the population (at least 40 million people) lack health insurance, ${ }^{12}$ almost $20 \%$ of the population lacks a usual source of care, ${ }^{13,14}$ the public health infrastructure remains weak, ${ }^{15,16}$ and mental health care struggles for recognition and parity. ${ }^{17}$ Health care is highly fragmented rather than seamlessly integrated. There exists renewed uncertainty about the adequacy of the health care workforce, ${ }^{18-26}$ confirmation of important disparities in health and health care, ${ }^{27}$ alarm about medical errors in all health care settings, ${ }^{28,29}$ and concern about accelerating health care spending, with a return to double-digit price escalation in health insurance premiums during a period of economic slump. ${ }^{30,31}$ Personal stories of despair and forecasts of collapse of the health care system are frequent fare in the media. ${ }^{32-34}$

Concern and frustration among family physicians with the direction of health care in the United States did not arise overnight. The 1990s began with a spirit of optimism that managed care would actually manage care and organize a fragmented and wasteful system, with family physicians and other primary care clinicians having a defined and central role. Soon this optimism gave way to great frustration when, instead of integration of care in the context of a sustained partnership between patients and their personal physicians, new layers of administrative decision makers - with oftentimes conflicting objectives - appeared. In this new, suddenly less positive, practice environment, family physicians found themselves painted as gatekeepers standing between their patients and care rather than being able to serve their patients as gateways to appropriate care.

Treating health care as a commodity that could be bought and sold, with large blocks of insured patients being moved annually from health plan to health plan, from provider to provider, and from system of care to 
system of care, eroded trust as relationships were fractured repeatedly. ${ }^{35}$ Few family physicians lack patients, but for many their work has devolved from meaningful service grounded in rich, personal relationships into jobs designed to manufacture health care that too often neither heals nor relieves suffering. ${ }^{36}$ While medical expenditures have increased, net income for physicians has declined, more so for primary care physicians than for specialists. ${ }^{37}$

In 1996 the Institute of Medicine (IOM), through the Committee on the Future of Primary Care, concluded that the nation's understanding of primary care was so poor, it was necessary to redefine it to establish a basis for study. The IOM definition clarified that primary care is not a discipline or specialty but a function as the essential foundation of a successful, sustainable health care system. ${ }^{38}$ Whereas many types of clinicians lay claims to providing primary care, the IOM concluded that the evidence pointed to family physicians, general internists, general pediatricians, and many nurse practitioners and physician assistants as the key primary care providers in the United States. That family physicians are key providers of primary care is indisputable; thus, family medicine and primary care are and will remain intertwined. ${ }^{39}$

The 1996 IOM report on primary care was prepared at a time when universal coverage and health care reform were anticipated on a national scale. Such was not to be, however, and the call for investment in primary care went largely unheeded. In the years since the issuance of that IOM report, the rate of growth in the subspecialty physician pool has continued to far exceed the rate of growth in family medicine and other primary care specialties. This disparity is reflected in the minimal growth in numbers of primary care physicians per 1,000 population compared with the growth experienced by non-primary-care specialists. Meanwhile, interest expressed by medical students in family medicine has declined to near crisis proportions, $^{40}$ as reflected in the declining match rates into family medicine residency training programs.

As the 21st century began, a sustained focus by the IOM on the quality of health care in the United States culminated in widely received publications that provided ominous warnings regarding the overall state of US health care. ${ }^{28,41}$ The 2001 IOM report, Crossing the Quality Chasm: A New Health System for the 21st Cen- tury $^{41}$ (the Chasm Report) made the startling assertion that the US health care system was so flawed it could not be fixed and an overhaul was required. This landmark report articulated 6 aims suggesting that the $21 \mathrm{st}$ century health care system should be:

1. Safe-avoiding injuries to patients from the care that is intended to help them

2. Effective-providing services based on scientific knowledge to all who could benefit and refraining from providing services that will not likely benefit them

3. Patient-centered-providing care that is respectful of and responsive to individual patient preferences, needs, and values, and ensuring that patient values guide all clinical decisions

4. Timely-reducing waits and sometimes harmful delays for both those who receive and those who give care

5. Efficient-avoiding waste, including waste of equipment, supplies, ideas, and energy

6. Equitable_-providing care that does not vary in quality because of personal characteristics, such as gender, race, ethnicity, geographic location, and socioeconomic status

These aims were widely perceived to be valid and were embraced by many family physicians as being consistent with their purpose and their aspirations. The Chasm Report went further and proposed rules that could guide the redesign of health care away from a decaying and failing system toward a new system of which the United States could be proud (Table 1). These rules were yet another call to action that was consistent with the goals and natural inclinations of family physicians and others committed to robust primary care for the nation.

The need for in-depth reevaluation and reform was not limited to the health system level. At the level of the discipline, family medicine was challenged by

\begin{tabular}{|ll|}
\hline Table 1. Simple Rules for the 21 st Century Health Care System \\
\hline Current Approach & New Rule \\
\hline $\begin{array}{ll}\text { Care is based primarily on visits } \\
\text { Professional autonomy drives variability }\end{array}$ & $\begin{array}{c}\text { Care is based on continuous healing relationships } \\
\text { values }\end{array}$ \\
\begin{tabular}{ll} 
Professionals control care & The patient is the source of control \\
Information is a record & Knowledge is shared and information flows freely \\
Decision making is based on training and & Decision making is evidence-based \\
experience & Safety is a system property \\
$\begin{array}{l}\text { Do no harm is an individual responsibility } \\
\text { Secrecy is necessary }\end{array}$ & Transparency is necessary \\
$\begin{array}{l}\text { The system reacts to needs } \\
\text { Cost reduction is sought }\end{array}$ & Needs are anticipated \\
Preference is given to professional roles & Waste is continuously decreased \\
rather than the system & Cooperation among clinicians is a priority \\
\hline Source: Crossing the Quality Chasm: A New Health System for the 21 st Century. ${ }^{41}$
\end{tabular} \\
\hline
\end{tabular}


contradictions and tensions, including confusion about family medicine being a reform movement (a solution) or an incumbent medical specialty (a problem), questions regarding whether family physicians should be considered generalists or specialists, debate about family medicine being vital for all or an option for a few, concerns regarding the knowledge base underlying training in family medicine, and uncertainty about the intrinsic value of some of the services provided by family physicians. ${ }^{42}$

\section{RESEARCH}

In this context, the leaders of 7 national family medicine organizations agreed it was essential that family medicine be responsive to the needs of the public and that the discipline take the lead toward constructive change. In response, the sponsoring organizations convened a historic conference, called Keystone III, to "examine the soul of the discipline of family medicine-to take stock of the present and grapple with the future of family practice." ${ }^{\prime 43}$ As a key preparatory step to the development of this report, the sponsoring organizations also chartered a national study conducted by independent researchers (Greenfield Consulting Group and Roper ASW), who worked collaboratively with a national strategic branding firm (Siegel \& Gale) The goal of the FFM research effort was to develop an objective understanding of the contemporary situation of family medicine in the United States based on unbiased quantitative and qualitative research. A full description of the methods is available as supplemental data in Appendix 1, which can be found online at http:

\section{//www.annfammed/org/cgi/content/full/2/suppl_1/}

$\mathrm{S} 3 / \mathrm{DC} 1$.

The research effort was guided by the following questions:

- What are people's perceived health care needs and what are their perceptions about how family physicians can meet those needs?

- Why, if at all, would people select and prefer family physicians as their primary physicians?

- What, if anything, is distinct about family physicians?

- Is there a group for which family medicine is irrelevant or makes no sense?

- What are the most promising, but unrealized, opportunities for family medicine?

- Do people desire the core attributes of family medicine (eg, first contact, continuity, community basis and context, comprehensiveness)?

- What challenges must family medicine overcome to meet contemporary expectations of people?

The study contractors began with qualitative research involving 15 interviews with thought leaders in and outside family medicine; 5 focus groups with family physicians; 13 focus groups with patients ( 2 groups with patients who had a family physician, 4 groups with patients across the adult age ranges who did not have family physicians, 2 rural groups, 1 chronically ill group, 1 Hispanic group, 1 Asian group, 1 African-American group, and 1 inner-city group); 3 focus groups with medical subspecialists; 3 with managed care/payers; 2 with medical students; 2 with resident physicians; and 1 with nurse practitioners. A national probability sample of the public was then queried using standard methods, sampling 1,031 patients, 125 additional parents of children, 300 family physicians, 75 academic family physicians, 75 non-primary-care medical specialists, 100 medical students, and 150 residents in medical training. Further one-on-one interviews were conducted with family physicians, payers, advocacy groups, benefits managers, Medicare/Medicaid administrators, nurse practitioners, and patients.

The qualitative and quantitative research produced a wealth of findings, ${ }^{44}$ including the following:

Family physicians are not well recognized by the public for what they are and what they do. Patients have a hard time differentiating family medicine from other primary care physician specialties, notably not distinguishing clearly between family medicine and general internal medicine. Indeed, the words "family" and "practitioner" were often found to confuse people and suggested to some that family physicians lack scientific background and competence.

Patients want their primary care physician to meet the following 5 basic criteria: to be in their insurance plan, to be in a location that is convenient, to be able to schedule an appointment within a reasonable period of time, to have good communication skills, and to have a reasonable amount of experience in practice.

Beyond the basic criteria, patients value the relationship with their physician above all else, including service. Patients value a physician who listens to them, who takes time to explain things to them, and who is able to coordinate effectively their overall care.

There is some skepticism regarding the concept of a comprehensive care provider who treats a broad range of health care problems. At least in part this reaction is based on the belief that it is unrealistic to expect any one physician to be able to stay current and maintain competence in all areas of medicine.

Family physicians were rated as "excellent" or "very good" by a clear majority of survey respondents on the top 5 relationship-related attributes identified by patients: being nonjudgmental, understanding, and supportive $_{i}$ being honest and direct; acting as a partner in maintaining health; listening effectively; and attending to patients' emotional and physical health. 
Although patients rank relationship-based attributes most highly, there is a tension between the desire to have a primary physician who is able to treat many illnesses and who treats the patient as a whole person, with the perception that it is not possible for any one physician to be knowledgeable and skilled in all areas of medicine.

The American public is enamored with science and technology, and they want their physicians to be technologically savvy. The public, however, does not associate family physicians with science and technology.

Patients expect high-quality health care, but instead of using quality as a selection criterion for physicians, they often assume that it exists. Patients tend to judge health care on relationships and rate family physicians highly in this regard. Because patients value relationship so highly and assume the quality of their care is high, they may forgive many of the inadequate service aspects of their care.

\section{Challenges and Opportunities for the Future}

Based on an analysis of the findings on patient perceptions and expectations, along with research on the attitudes and perceptions of family physicians, medical students, subspecialists, family medicine residents, and residents in other specialties, 5 major challenges were identified that will influence family medicine's future viability:

1. Promoting a broader, more accurate understanding of the specialty among the public

2. Identifying areas of commonality in a specialty whose strength is its wide scope and locally adapted practice types

3. Winning respect for the specialty in academic circles

4. Making family medicine a more attractive career option

5. Addressing the public's perception that family medicine is not solidly grounded in science and technology

After reviewing the research findings and considering the implications of these 5 challenges, the FFM Project Leadership Committee concluded that unless there are changes in the broader health care system and within the specialty, the position of family medicine in the United States may be untenable in a 10- to 20-year time frame, which would be detrimental to the health of the American public. The FFM Project Leadership Committee further concluded that changes must occur within the specialty, as well as within the broader health care system, to ensure the ability of family medicine to meet these challenges and continue to fulfill its unique mission and role. These conclusions confirmed the importance of developing an FFM action plan to ensure the continued relevance and viability of the specialty.
Considerable evidence supports the contemporary importance of family physicians in the US health care system. For example, care by generalists uses few resources while producing similar health outcomes for patients with chronic disease. ${ }^{45,46}$ Many counties would become shortage areas without their family physicians (Figures 1 and 2). Looking internationally, countries that emphasize primary care have better population health at lower cost. ${ }^{39}$ It is not surprising that the World Health Organization calls for an increased presence of primary health care in order to support progress in health. ${ }^{47}$

In addition, as Figure $3^{48}$ illustrates, more people receive formal health care in physicians' offices-particularly primary care physicians' offices - than any other location; indeed, in an average month 14 times more people receive care in a primary care physician's office than hospital inpatients. Furthermore, people beset with the nation's high-priority health problems rely primarily on family physicians and general internists as their usual source of care (Table 2). ${ }^{49}$ Indeed, the latest nationally representative data confirm that family medicine continues to be the medical specialty providing more office visits (199 million) than any other specialty. ${ }^{50}$

Despite these seemingly positive indicators of the importance of family medicine, there are a number of disturbing trends. For example, the proportion of visits to family physicians for acute, chronic, and preventive care has been in slow decline overall. Also, there was a steady and progressing decline from 1980 through 1999 in the percentage of US physicians who were family physicians. ${ }^{51}$

After analyzing all of these data and trendsboth positive and negative-the FFM Project Leadership Committee concluded that family medicine continues to meet a fundamental public need for integrated, relationship-centered health care ${ }^{52}$ and that the problems afflicting family medicine do not include irrelevance or obsolescence. Functioning within a health care system that is broadly viewed as flawed and failing, family medicine nevertheless finds many of its core attributes highly sought after by the American public. The future contributions and well-being of the discipline lie, in part, in the ability of family medicine to rearticulate its vision and competencies in a fashion that has greater resonance with the public, while at the same time substantially revising the organization and processes by which care is delivered.

Even within the constraints of the current flawed health care system, there are great opportunities for family physicians to redesign their models of practice to better serve patients while achieving 


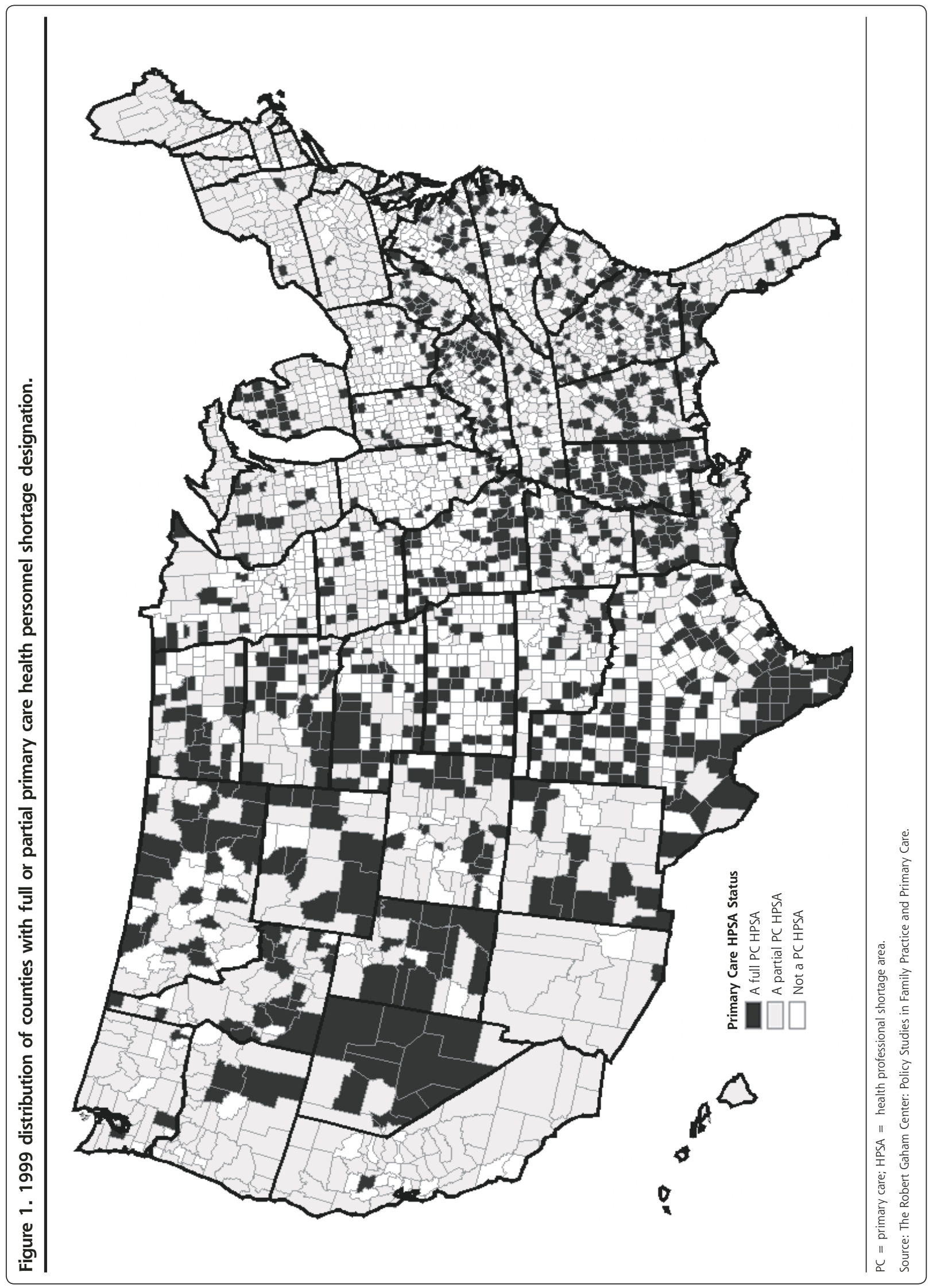




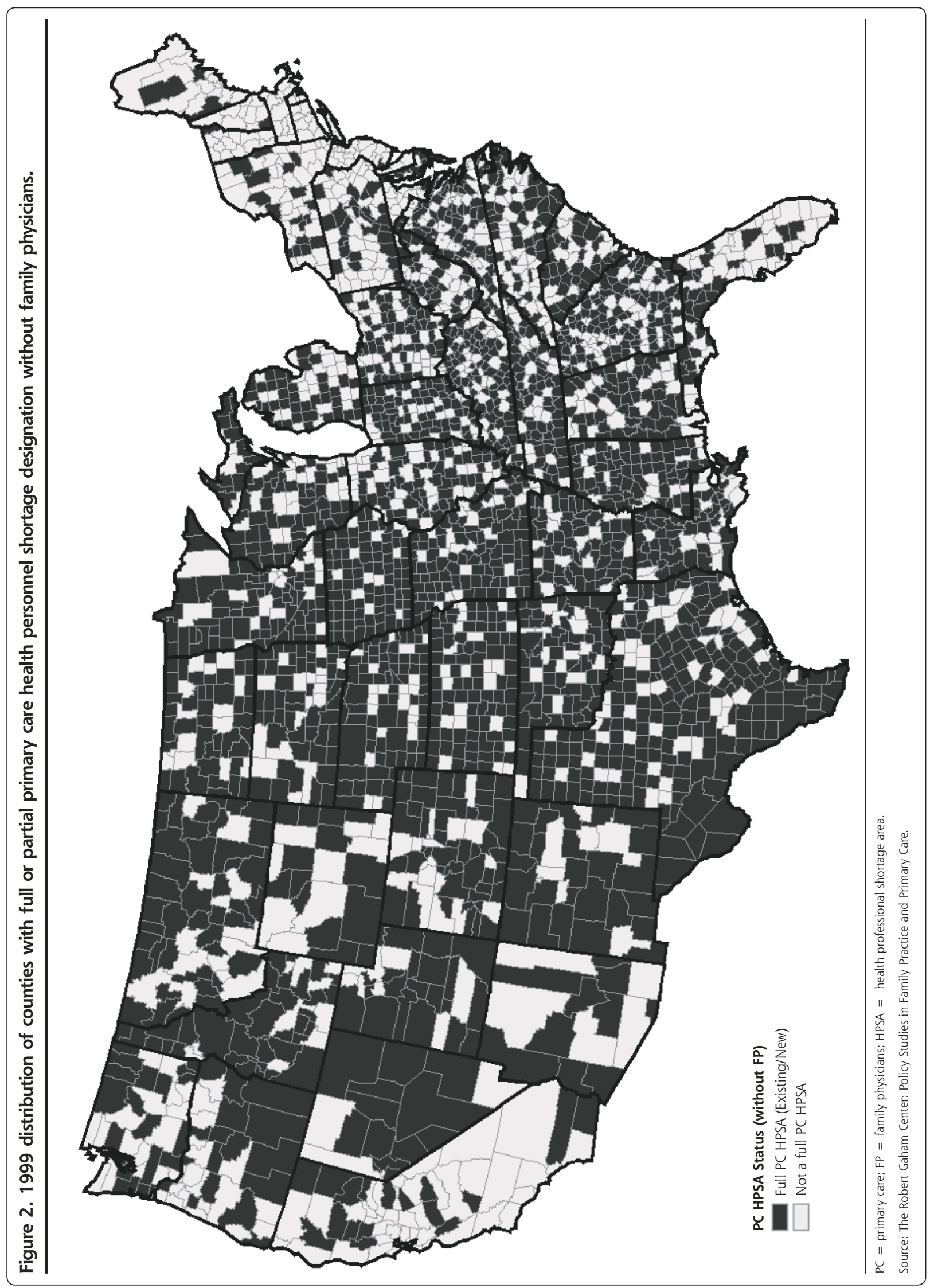

ANNALS OF FAMILY MEDICINE + WWW.ANNFAMMED.ORG + VOL. 2, SUPPLEMENT 1 + MARCH/APRIL 2004 
Figure 3. The ecology of medical care revisited.

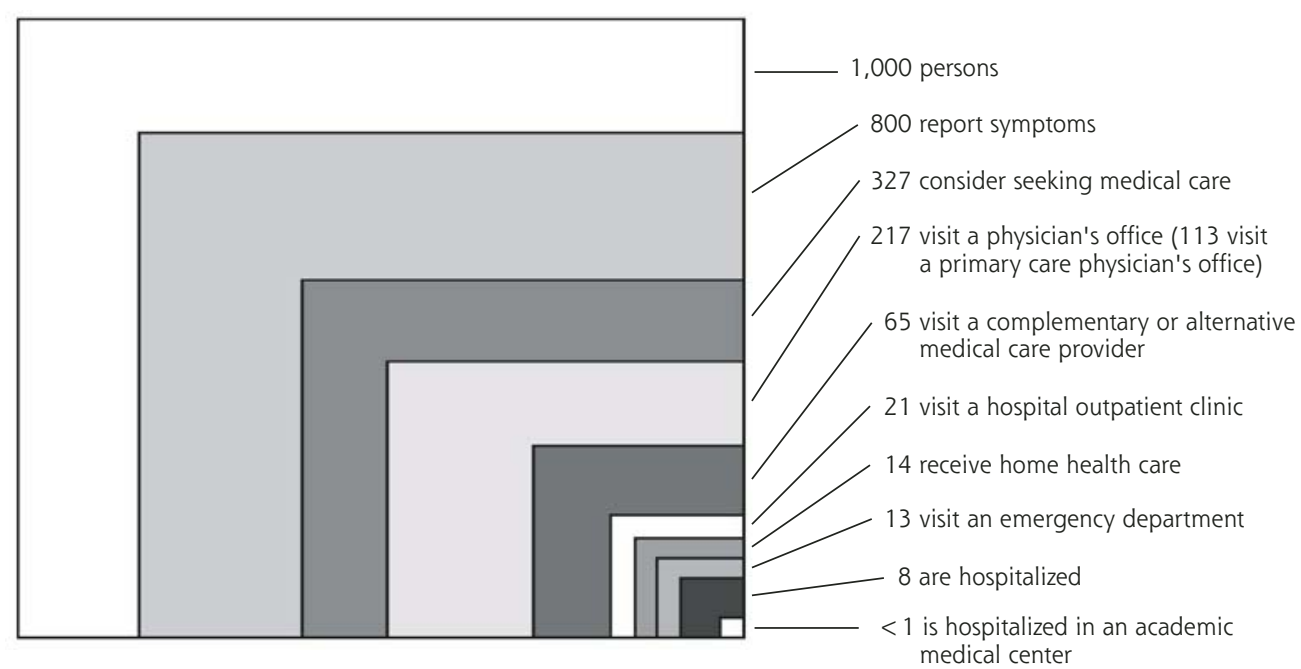

Note: All numbers refer to discrete individual persons and whether or not they received care in each setting in a typical month

From: Green LA, Fryer GE Jr, Yawn BP, Lanier D, Dovey SM. The ecology of medical care revisited. N Engl J Med. 2001;344:2021-2025. ${ }^{48}$ Reprinted with permission from the Massachusetts Medical Society.

greater economic success. In fact, because major elements of the US health care system are in disarray, a climate exists in which the reconfiguration and reengineering of the basic elements of office-based family medicine may meet less resistance than would be the case in a system more generally viewed as performing adequately. To realize fully the aspirations of the discipline, however, there must be major changes in the organization and financing of health care services in the United States as well as within the specialty itself. pline has been grounded in the core values of continuing, comprehensive, compassionate, and personal care provided within the context of family and community. These core values of family medicine are responsible for much that the public currently values and trusts in family physicians. They have shaped the identity of individual family physicians and contributed to establishing a legitimate position for family physicians in academia and in the larger medical community. ${ }^{53,54} \mathrm{~A}$ challenge to the specialty is to articulate these core values in a sufficiently distinctive way so they are rec-

\section{FOUNDATION FOR A REINVIGORATED DISCIPLINE}

In preparing to move the specialty of family medicine forward, it is important first to articulate the core values, the key characteristics, and the identity that provide the foundation for family medicine and position the specialty favorably to address the challenges and opportunities of the future.

\section{Core Values}

The development of family medicine and its identity as a disci-
Table 2. Distribution by Specialty of the Usual Source of Care for People With Selected Conditions and a Physician as That Usual Source

\begin{tabular}{|c|c|c|c|c|}
\hline Condition & $\begin{array}{c}\text { Family Medicine } \\
\%\end{array}$ & $\begin{array}{c}\text { General } \\
\text { Internal } \\
\text { Medicine } \\
\%\end{array}$ & $\begin{array}{c}\text { General } \\
\text { Pediatrics } \\
\%\end{array}$ & $\begin{array}{c}\text { All Others } \\
\%\end{array}$ \\
\hline $\begin{array}{l}\text { Atherosclerotic } \\
\text { cardiovascular } \\
\text { disease }\end{array}$ & 56 & 31 & 0.0 & 14 \\
\hline Stroke & 56 & 34 & 0.9 & 9 \\
\hline Hypertension & 63 & 28 & 0.2 & 8 \\
\hline Diabetes & 67 & 23 & 0.6 & 10 \\
\hline Cancer & 60 & 26 & 2.3 & 11 \\
\hline $\begin{array}{l}\text { Chronic obstructive } \\
\text { pulmonary disease }\end{array}$ & 62 & 22 & 5.4 & 11 \\
\hline Asthma & 58 & 15 & 20.8 & 6 \\
\hline Anxiety/depression & 62 & 20 & 7.0 & 11 \\
\hline
\end{tabular}


ognized by the public as central to what patients seek from their personal physician. To date, family medicine has not done an adequate job of communicating its core values to the public.

Family physicians are committed to continuing, comprehensive, compassionate, and personal care for their patients. They are concerned with the care of people of all ages, and understand that health and disease involve the mind, body, and spirit and depend in part on the context of patients' lives as members of their family and community. ${ }^{38,52,55}$ These core values are congruent with the IOM aims and rules for the $21^{\text {st }}$ century health care system and likely are essential to their realization.

To achieve top performance, family physicians must work in practice environments that fully promote these transforming values. They must practice on a daily basis scientific, evidence-based, patient-centered care; they must accept a measure of responsibility for the appropriate and wise use of resources; and they must work in teams within and beyond their practice setting, focusing on the integration of care for each of their patients. Success in these endeavors requires systems that enhance quality by maintaining access to comprehensive, compassionate, personalized care while reducing unwanted variability in diagnosis and treatment by reducing errors of misuse, overuse, and underuse and by measuring results for individuals and populations under their care. ${ }^{39,41}$

Building on these core values, the Project Leadership Committee identified the following functions of a family physician: a family physician offers continuing, comprehensive, compassionate, and personal health care in the context of family and community. At the core of the specialty is the concept of integration of health care for patients of both sexes across the full spectrum of ages in the context of a continuing relationship. Family physicians have skills in diagnos- ing and treating illness, in performing diagnostic and therapeutic procedures, and in managing relationships, information, and processes. The care provided by family physicians is based on evidence and is outcome oriented. Family physicians are actively involved in the pursuit of new knowledge that will increase understanding of health and illness and improve the delivery of health care.

\section{Key Characteristics and Identity}

Building on the 5 key characteristics of family physicians that were identified through the study (Table 3), ${ }^{44}$ the Siegel \& Gale consultants proposed the following identity statement for family physicians: family physicians are driven by the need to help make people whole by humanizing medicine. After considerable discussion over many months, the Project Leadership Committee adopted the following identity statement, which incorporates key concepts integral to the identity of family physicians, including a commitment to fostering health, an orientation toward integrating health care for the whole person, a talent for humanizing medicine, and a dedication to providing sciencebased high-quality care:

Family physicians are committed to fostering bealth and integrating bealth care for the whole person by bumanizing medicine and providing science-based bigh-quality care.

Exactly how these characteristics are stated is less important than a recognition of their contemporary importance and that they enhance the core values of family physicians the public finds attractive and valuable. These key attributes and core values are what characterize family physicians (Table 3 ).

The public is hungry for these attributes as the current health care system becomes increasingly fragmented and impersonal. ${ }^{44,56-59}$ To realize fully the potential of the specialty and to meet completely the needs of patients, however, changes are needed in the follow-

\section{Table 3. Key Attributes of Family Physicians}

\begin{tabular}{|c|c|}
\hline Attribute & Description \\
\hline $\begin{array}{l}\text { A deep understanding of the } \\
\text { dynamics of the whole person }\end{array}$ & $\begin{array}{l}\text { This approach leads family physicians to consider all the influences on a person's health. It helps to integrate } \\
\text { rather than fragment care, involving people in the prevention of illness and the care of their problems, } \\
\text { diseases, and injuries }\end{array}$ \\
\hline $\begin{array}{l}\text { A generative impact on patients' } \\
\text { lives }\end{array}$ & $\begin{array}{l}\text { This terminology comes from Erik Erikson's work on personality development. Family physicians participate } \\
\text { in the birth, growth, and death of their patients and want to make a difference in their lives. While provid- } \\
\text { ing services that prevent or treat disease, family physicians foster personal growth in individuals and help } \\
\text { with behavior change that may lead to better health and a greater sense of well-being }\end{array}$ \\
\hline $\begin{array}{l}\text { A talent for humanizing the health } \\
\text { care experience }\end{array}$ & $\begin{array}{l}\text { The intimate relationships family physicians develop with many of their patients over time enable family } \\
\text { physicians to connect with people. This ability to connect in a human way with patients allows family physi- } \\
\text { cians to explain complex medical issues in ways that their patients can understand. Family physicians take } \\
\text { into account the culture and values of their patients, while helping them get the best care possible }\end{array}$ \\
\hline A natural command of complexity & $\begin{array}{l}\text { Family physicians are comfortable with uncertainty and complexity. They are trained to be inclusive, to con- } \\
\text { sider all the factors that lead to health and well-being - not just pills and procedures }\end{array}$ \\
\hline $\begin{array}{l}\text { A commitment to multidimen- } \\
\text { sional accessibility }\end{array}$ & $\begin{array}{l}\text { Family physicians are not only physically accessible to patients and their families and friends, they are also } \\
\text { able to maintain open, honest and sharing communications with all who are involved in the care process }\end{array}$ \\
\hline
\end{tabular}


ing 3 broad areas: (1) clinical practice, or how family physicians' medical practices are organized and function; (2) medical education, or how family physicians are trained and how they maintain and update their knowledge and skills throughout their careers; and (3) health system, or how the US health care system is organized and financed.

\section{BRINGING ABOUT CHANGES IN CLINICAL PRACTICE}

\section{Reintegration of Patient, Physician, and Practice Through a New Model}

The current shortcomings and dissatisfaction with the US health care system provide family physicians with a compelling opportunity to improve the health of the nation and shape their own destinies by redesigning their model of practice. The 6 aims and 10 new rules identified in the IOM Chasm Report, along with the key characteristics and identity statement for family medicine developed as part of this study, point the way to a proposed new model of practice for family medicine (New Model) that is traditional enough to reflect and sustain enduring principles and values, familiar enough to be understandable, bold enough to attract interest and funding, and practical enough to be implemented in the immediate future.

A number of the elements of the New Model may seem familiar to and even part of the practices of many family physicians. What makes the model new is that it is centered primarily and explicitly on the needs of the patient, it incorporates new concepts from industrial engineering and customer service, and it integrates these needs and concepts into a coherent and comprehensive approach to care. Although some family physicians have incorporated one or more of the characteristics of the New Model into their practices, few, if any, have designed practices that integrate all of these elements.

The critical bridge between the expression of the core values of family medicine as a medical discipline and the New Model of care, in which the family physician's patients will be cared for, is the relationship between the physician, the practice, and the patient. The family physician's commitment to fostering health and integrating health care has major implications for the redesign of the specialty of family medicine. The challenge is one of configuring family medicine in such a way that patients will feel not only cared for but also guided appropriately through and represented within the larger health care system. Meeting this challenge will require a reintegration of the patient, the practice, and other providers and organizations in the context of the community and, ultimately, the larger health care system. ${ }^{60}$ Only through such a reintegration will safe, effective, patient-centered, timely, efficient, and equitable care be possible.

For family medicine to contribute substantially to this reintegration, family physicians will need to reconceptualize their role and redesign their practices accordingly. Looking to the future, family physicians must not only have the requisite skills in diagnosis, treatment, and performance of procedures, they must also demonstrate competencies in managing relationships, information, and processes. ${ }^{61-63}$

\section{Managing Relationships}

Because a continuous healing relationship is the essence of care, family physicians must be able to develop and sustain partnerships with patients over time, establish and maintain systems and procedures that support those relationships, and enable timely access to the services their patients need.

\section{Managing Information}

The complexity of caring for patients with acute and chronic problems over time and managing preventive services for populations of patients requires the involvement of many health care professionals working in well-organized systems and supported by information technology. ${ }^{64}$ It requires partnering with patients. Family physicians will rely increasingly on information systems and electronic health records to provide assessments, checklists, protocols, and access to patient education and clinical support. Clinical information must be maintained in a format that allows for ready search, retrieval, and information transfer while protecting the privacy and confidentiality of patients' medical records. Having electronic health records with a relational database design and meeting national technical standards are essential. The paper medical record can no longer provide a sufficient foundation for clinical care and research within family medicine.

\section{Managing Processes}

All clinicians work in systems of care. Some family physicians work in small systems; others work in extremely large systems. Family physicians and their health professional colleagues must assume responsibility for the constant assessment and improvement of their care. Patients, the central focus of the family physician's clinical enterprise, are crucial participants in many of the processes of care and must share responsibility for receiving appropriate and successful care. Working together on behalf of patients requires teamwork that occurs within a complex set of relationships and services. It requires skillful management with appropriate authority and collaboration 


\begin{tabular}{|c|c|}
\hline Characteristic & Description \\
\hline Personal medical home & $\begin{array}{l}\text { The practice serves as a personal medical home for each patient, ensuring access to comprehensive, integrated } \\
\text { care through an ongoing relationship }\end{array}$ \\
\hline Patient-centered care & $\begin{array}{l}\text { Patients are active participants in their health and health care. The practice has a patient-centered, relationship- } \\
\text { oriented culture that emphasizes the importance of meeting patients" needs, reaffirming that the fundamental } \\
\text { basis for health care is "people taking care of people"65 }\end{array}$ \\
\hline Team approach & $\begin{array}{l}\text { An understanding that health care is not delivered by an individual, but rather by a system, }{ }^{66} \text { which implies a } \\
\text { multidisciplinary team approach for delivering and continually improving care for an identified population }{ }^{41,67}\end{array}$ \\
\hline $\begin{array}{l}\text { Elimination of barriers to } \\
\text { access }\end{array}$ & $\begin{array}{l}\text { Elimination, to the extent possible, of barriers to access by patients through implementation of open scheduling, } \\
\text { expanded office hours, and additional, convenient options for communication between patients and practice staff }\end{array}$ \\
\hline Advanced information systems & $\begin{array}{l}\text { The ability to use an information system to deliver and improve care, to provide effective practice administration, } \\
\text { to communicate with patients, to network with other practices, and to monitor the health of the community. }{ }^{68} \\
\text { A standardized electronic health record (EHR), adapted to the specific needs of family physicians, constitutes } \\
\text { the central nervous system of the practice }\end{array}$ \\
\hline Redesigned offices & $\begin{array}{l}\text { Offices should be redesigned to meet changing patient needs and expectations, to accommodate innovative } \\
\text { work processes, and to ensure convenience, comfort, and efficiency for patients and clinicians }\end{array}$ \\
\hline Whole-person orientation & $\begin{array}{l}\text { A visible commitment to integrated, whole-person care through such mechanisms as developing cooperative } \\
\text { alliances with services or organizations that extend beyond the practice setting, but which are essential for } \\
\text { meeting the complete range of needs for a given patient population. }{ }^{38} \text { The practice has the ability to help } \\
\text { guide a patient through the health care system by integrating care-not simply coordinating it }\end{array}$ \\
\hline $\begin{array}{l}\text { Care provided within a } \\
\text { community context }\end{array}$ & A culturally sensitive, community-oriented, population-perspective focus \\
\hline Emphasis on quality and safety & $\begin{array}{l}\text { Systems are in place for the ongoing assessment of performance and outcomes and for implementation of } \\
\text { appropriate changes to enhance quality and safety }\end{array}$ \\
\hline Enhanced practice finance & Improved practice margins are achieved through enhanced operating efficiencies and new revenue streams \\
\hline $\begin{array}{l}\text { Commitment to provide family } \\
\text { medicine's basket of services }\end{array}$ & $\begin{array}{l}\text { A commitment to provide patients with family medicine's full basket of services-either directly or indirectly } \\
\text { through established relationships with other clinicians }\end{array}$ \\
\hline
\end{tabular}

as well as a mindset of vigilance and continuous process improvement. ${ }^{38}$ Table $4^{38,41,65-68}$ summarizes the orientation and characteristics that New Model practices will need to embrace.

Two important points should be kept in mind in reviewing the characteristics of New Model practices. First, changes to current health care payment mechanisms that promote more equitable reimbursement will be necessary for some of the benefits of the New Model to be realized fully. Many aspects of the New Model, however, can be implemented independent of reimbursement reform. Second, although some of the New Model characteristics have been implemented on a piecemeal basis by innovative family physicians, it is the entire spectrum of characteristics that represents the change in orientation from the traditional model of family medicine to the New Model.

\section{Personal Medical Home}

In addition to the changes that family physicians can implement to enhance patient access to care, steps must be taken to ensure every American has a personal medical home* that serves as the focal point through which all individuals - regardless of age, sex, race, or socioeconomic status-receive a basket of acute, chronic, and preventive medical care services. Through their medical home, patients can be assured of care

* By the American Academy of Pediatrics, and incorporated herein, with appreciation. that is not only accessible but also accountable, comprehensive, integrated, patient-centered, safe, scientifically valid, and satisfying to both patients and their physicians.

\section{Patient-Centered Care}

The cornerstone of the New Model is patient-centered care based on a patient-physician relationship that is highly satisfying and humanizing to the patient and the physician (as well as other practice clinicians). The starting place for helping to foster health and integrate health care will be to establish a culture within each family medicine setting. In the New Model, the patient, not the physician, occupies center stage. From first contact through the completion of the care episode, the patient must meet with consistent and competent care. In the New Model, all patients will receive care that is culturally and linguistically appropriate.

New Model practices strive to meet patient and community needs for integrated care by giving patients what they want and need-including preventive care, acute care, rehabilitative care, chronic illness care, and supportive care-when they want and need it by anticipating patient needs and designing services to meet those needs.

\section{Whole-Person Orientation}

The focus of New Model practices will be comprehensive, integrative care designed to meet the complete 
range of needs of the community served by the practice. ${ }^{37}$ Although patients are ultimately responsible for their health, the family physician in a New Model practice will conceive of himself or herself as the chief consultant and advisor for each patient's health care. The practice will provide or integrate all of their patients' care. Family physicians will consider not only what they can do for their patients but also what other resources and services are available in the community to meet patient needs. When a family physician cannot provide specific services personally, he or she will refer patients to the appropriate source of care for their particular needs.

The New Model practice will continue to provide care for both sexes, across all ages, socioeconomic classes, and settings. Accepting the complexity of health and health care, the New Model practice will provide multiple ways for patients to access care and will ensure optimal care to people regardless of socioeconomic status. Such a practice will be a system that models the very whole-person orientation that patients can expect in the care they receive. Although the office setting will continue to be an important site for care, it is important to emphasize that to integrate patient care effectively, future family physicians will need to be prepared to provide services in a variety of settings, including hospitals and long-term care facilities; in short, they will provide care wherever the family physician's services are needed by patients.

\section{Team Approach}

Patient care in the New Model will be provided through a multidisciplinary team approach and grounded in a thorough understanding of the population served by the practice. In addition to nurses and clerical personnel, staffing will often include physician assistants and nurse practitioners as well as nutritionists, health educators, behavioral scientists, and other professional and lay partners. Some of these staff may work in the practice only on a part-time basis. Depending on the particular circumstances, patients may receive care from any one of several members of the multidisciplinary team rather than from a family physician.

A cooperative effort among all clinicians will be the cultural norm, and it will be understood that the practice is more than the sum of its individual parts. Practice staff will share in decision making regarding patient care with explicit accountability for their performance to patients, to each other, and to each patient's personal physician. Systems of care will be honored and supported. New Model practices will develop collaborative relationships with subspecialists for the purposes of improving and better integrating patient care. In some cases, subspecial- ists may see patients on-site at New Model practice facilities.

\section{Elimination of Barriers to Access}

Under the New Model, barriers to patient access will be minimized. Practices will use an open scheduling model for patient visits (ie, the patient usually will be able to make an appointment for the same day, regardless of the type of problem or visit required), while offering flexible and expanded office hours. The practice will provide a convenient mechanism for asynchronous communication for nonurgent issues (eg, voice mail and e-mail), as well as telephone communication with a person-not an answering machine or voice mail-24 hours a day, 7 days a week for urgent matters. In areas where multiple practices exist, New Model practices will be networked for providing urgent services on site in one practice when other practices are closed, with communication links in place to assure seamless communication to the patient's physician regarding the urgent care provided.

Interactions will not be limited to traditional, individual, face-to-face encounters between the patient and the family physician. Where feasible and as systems evolve, New Model practices will develop a Web portal and will use secure e-mail to provide additional, convenient options for communication between patients and practice staff. Patients will be able to make appointments online through the practice Web site and will be able to access online patient education materials appropriate to their health status.

\section{Information Systems}

A standardized electronic health record, adapted to the specific needs of family physicians and the patients they serve, will constitute the central nervous system of the New Model practice. However the electronic health record is structured, high priority must be given to assuring that information from multiple, diverse sources (hospital, office, long-term care facility, etc) is integrated into a single system to support the comprehensive information needs on which primary care practices depend. Similarly, electronic health record systems must permit the collection, analysis, and reporting of the clinical decisions and their outcomes that primary care clinicians make every day. The system should provide an informatics infrastructure that supports practice-based research, quality improvement, and the generation of new knowledge.

This electronic information system must integrate easily into the daily practice of family physicians, must be accessible at reasonable cost, and must result in a major enhancement to the efficiency and quality of the care that is delivered. As a replacement for or an 
important adjunct to traditional record keeping, the system must be user friendly, flexible enough to integrate a variety of management tasks, stable and reliable, and delivered with appropriate training for physicians with highly variable levels of comfort and experience with such systems.

The information system for the New Model practice should be based on common health information technology standards, should be interoperable across all levels of care, and should be capable of collecting a wide range of demographic information about the patient population. The system should contain an up-to-date and accurate problem and medications list for each patient and information about each patient encounter. It also should have an export function that is capable of sharing data elements in a standardized format so they can be analyzed in conjunction with data from other practices to create quality parameters and assessment measures.

The information systems of New Model will facilitate the integration of the care of the whole person in the context of their family and community. These systems will also include evidence-based clinical practice guidelines for enhancing the care of those individual conditions most commonly encountered by family physicians. They will have an order entry and referral tracking system, a managed care organization-specific pharmacy formulary, and Web-enabled access to data repositories, with appropriate levels of security.

Furthermore, information systems of the New Model practice will be able to generate chronic disease registries, which will ensure that patients can be recalled for care at appropriate time intervals, and able to track health maintenance interventions and generate physician and patient reminders for personalized preventive services. It will be integrated with common practice management and billing systems; have some availability to patients by means of a Web interface for entry of self-care data, patient history data, health-related quality-of-life measures, mental health screening questionnaires, and other applications; and be able to support practice-based clinical research using electronic audits concerning the costs, processes, and outcomes of care (including the Health Plan Employer Data and Information Set or similar measures).

In addition to the electronic health record, the New Model practice will have computerized decision support systems_-ideally Web based_to help patients make better, more informed health care decisions and to facilitate the process through which the family physician explains patient care options. In addition, justin-time information systems for physicians will allow rapid retrieval of best, up-to-date evidence at the point of care. This system will be sufficiently standardized to allow access upon written release when patients require care away from their personal medical home.

\section{Redesigned Offices}

New Model practice facilities will be designed to accommodate staffing patterns that differ from the current model, including most notably a broader array of health professionals working together as part of a multidisciplinary team. Family medicine offices will be designed specifically to meet the needs and expectations of the local community. Offices will be convenient, attractive, and functional and will have private, comfortable space to accommodate group visits with selected patients who share common health concerns.

The traditional waiting room will be a thing of the past, replaced by a patient resource center with a patient library, computer work stations with ready access to online health education materials, and patient information-gathering stations. Practices will be equipped with sufficient technology, staff, and supplies to be able to provide on-site a comprehensive set of diagnostic services, testing for important genetic predispositions, and performance of common therapeutic procedures.

\section{Focus on Quality and Safety}

The New Model practice will seek to improve continuously the quality of patient care. Practices will document quality and safety through ongoing analyses of practice patient care data. Patient feedback will be solicited to ensure that the practice is meeting patients' expectations, satisfying their needs for access to the practice, and responding to the needs of increasingly diverse populations. Each practice will develop and use a structured, recurring administrative mechanism to examine the measurements of the practice and the patients under care. Practice staff, along with representative patients, will be included in these quality improvement processes. New Model practices will place a high priority on taking steps to ensure patients' safety within the practice, including use of electronic data and decision support systems.

\section{Enhanced Practice Finance}

While vigorous efforts are pursued to secure equitable reimbursement for the services provided by family physicians, the dictum "no margin, no mission" will be taken seriously within New Model practices. Improved operating efficiencies will decrease practice expenses and contribute to improved practice margins. Practices will compete for gaining a portion of patients' discretionary health care spending. New Model practices will be organized to accommodate all payment options while advocating for health insurance coverage of all Americans. 


\section{Table 5. Basket of Services in the New Model of Family Medicine}

Health care provided to children and adults

Integration of personal health care (coordinate and facilitate care)

Health assessment (evaluate health and risk status)

Disease prevention (early detection of asymptomatic disease)

Health promotion (primary prevention and health behavior/lifestyle modification)

Patient education and support for self-care

Diagnosis and management of acute injuries and illnesses

Diagnosis and management of chronic diseases

Supportive care, including end-of-life care

Maternity care; hospital care

Primary mental health care

Consultation and referral services as necessary

Advocacy for the patient within the health care system

Quality improvement and practice-based research

\section{The Basket of Services in the New Model}

The New Model practice will commit to providing the full basket of clinical services offered by family medicine* (Table 5), either directly through its own clinicians or indirectly through established, ongoing relationships with experienced clinicians outside the practice. Even if the practice does not have the expertise or interest to provide directly a particular type of care within the basket of services, the patient nevertheless will be assured of receiving that care and having that care effectively coordinated and integrated.

The basket of services that patients can be assured of receiving through a New Model practice will include the management and prevention of acute injuries and illnesses, chronic diseases, health promotion, wellchild care, child development and anticipatory guidance services, and rehabilitation and supportive care across health care settings. State-of-the-art chronic disease management will be an important part of the services provided by New Model practices. The care of patients with chronic diseases will utilize a community population-based approach, including the use of disease registries and community-oriented primary care methods. The practice will adhere to evidence-based clinical practice guidelines, which will be embedded into the electronic health record, and will participate in continuous quality improvement and practice-based research. The management of patients with chronic diseases will involve the full multidisciplinary team and will include some care of patients in their homes. The use of telemedicine and other new technologies will be explored as ways of enhancing the management of these patients

* By the College of Family Physicians of Canada, and incorporated herein, with appreciation.
The New Model office will put into practice the most current public health concepts and strategies while providing excellent preventive care across the individual life cycle and age spectrum. Preventive interventions will be implemented based on the quality of supportive evidence. Standard and personalized health risk assessments will be utilized for risk factor identification. The electronic health record will play a key role in tracking adherence to prevention guidelines and in continuously improving the quality of the preventive care provided by the practice. Health behavior and lifestyle modification skills will be essential to the multidisciplinary team providing preventive care in the practice.

Family physicians will participate in the care of their hospitalized patients. Depending upon local circumstances, they might not always assume full or primary responsibility for patient care in the inpatient setting. In all cases, though, there will be seamless transitions between different settings of care, and the approach taken to hospital care will support the maintenance of continuing, healing relationships with patients.

The flexibility and adaptability of the New Model will accommodate variation from practice to practice in the specific services provided, depending on the geographic location of the practice, the unique needs of the community being served, the physicians' interests and training, and the availability of staff. For example, practices will vary in the range of diagnostic and therapeutic procedures performed, in the amount and intensity of hospital care provided, and in the extent to which they provide intrapartum maternity care. All family physicians, however, will share a common commitment to provide or coordinate all care specified in the family physician's basket of services, thereby serving as effective personal medical homes for their patients.

Table 6 presents a simple comparison between the traditional model of practice and the New Model.

\section{BRINGING ABOUT CHANGES IN TRAINING AND CONTINUING DEVELOPMENT}

\section{Graduate Medical Education}

Unlike many other specialties, family medicine is not defined by a specific disease, organ or body system, by the age or sex of the patient population served, or by the setting in which care is provided. Rather, the family physician's knowledge, skills, and attitudes encompass all ages, both sexes, a myriad of complaints and illnesses, and multiple settings. As such, the education of the family physician is one that emphasizes a process: the patient-physician relationship and problem definition/ prioritization. The family physician is an expert in this approach

Family medicine residency education began with 


\section{Table 6. Comparison of Traditional vs New Model Practices}

\begin{tabular}{|c|c|}
\hline Traditional Model of Practice & New Model of Practice \\
\hline Systems often disrupt the patient-physician relationship & Systems support continuous healing relationships \\
\hline $\begin{array}{l}\text { Care is provided to both sexes and all ages; includes all stages of the } \\
\text { individual and family life cycles in continuous, healing relationships }\end{array}$ & $\begin{array}{l}\text { Care is provided to both sexes and all ages; includes all stages of the } \\
\text { individual and family life cycles in continuous, healing relationships }\end{array}$ \\
\hline Physician is center stage & Patient is center stage \\
\hline Unnecessary barriers to access by patients & Open access by patients \\
\hline Care is mostly reactive & Care is both responsive and prospective \\
\hline Care is often fragmented & Care is integrated \\
\hline Paper medical record & Electronic health record \\
\hline Unpredictable package of services is offered & $\begin{array}{l}\text { Commitment to providing directly and/or coordinating a defined basket } \\
\text { of services }\end{array}$ \\
\hline Individual patient oriented & Individual and community oriented \\
\hline Communication with practice is synchronous (in person or by telephone) & $\begin{array}{l}\text { Communication with the practice is both synchronous and asynchronous } \\
\text { (e-mail, Web portal, voice mail) }\end{array}$ \\
\hline Quality and safety of care are assumed & $\begin{array}{l}\text { Processes are in place for ongoing measurement and improvement of } \\
\text { quality and safety }\end{array}$ \\
\hline Physician is the main source of care & Multidisciplinary team is the source of care \\
\hline Individual physician-patient visits & $\begin{array}{l}\text { Individual and group visits involving several patients and members of } \\
\text { the health care team }\end{array}$ \\
\hline Consumes knowledge & Generates new knowledge through practice-based research \\
\hline Experience based & Evidence based \\
\hline Haphazard chronic disease management & Purposeful, organized chronic disease management \\
\hline Struggles financially, undercapitalized & Positive financial margin, adequately capitalized \\
\hline
\end{tabular}

a number of innovations more than 30 years ago, changes that have influenced residency education in other specialties. Its full potential has not yet been realized, however. The following changes in both the practice environment and in residency education since the specialty was created have resulted in a need to reevaluate and revise the traditional family medicine training model: few residency graduates now go into solo practice, only about one third include maternity care in their scope of services, and some provide little or no inpatient care. ${ }^{69}$ In addition, evidence-based, quality- and outcome-oriented medicine are driving forces today as opposed to being mere concepts 3 decades ago.

Given these and other changes, it is clear that the traditional family medicine curriculum, although successful in the past, will be challenged to meet the anticipated needs of the health care system of the future. Family medicine, at both the residency and medical school levels, must refocus and create models that support future needs by educating family physicians whose core knowledge, skills, and attitudes have been measured and whose special interests and competencies have been developed and locally adapted to a level of unquestioned excellence.

The core experience responsible for the formation of the family physician is residency training; therefore, the training of future family physicians will require a culture of innovation and experimentation to identify and evaluate new educational approaches. Family physicians of tomorrow will need to have knowledge, skills, and attitudes that go beyond diagnosis and treatment of disease, including skills in health promotion designed to maximize each patient's potential. In addition, the family physician of the future will need to be an expert manager of knowledge, relationships, and processes.

In keeping with the FFM research findings, the results of other recent studies, and the mission of the FFM project, it is clear the training of future family physicians must be grounded in evidence-based medicine that is relevant to the care of the whole person in a relationship and community context. It also must be technologically up to date, built on a solid foundation of clinical science, and strong in the components of interpersonal and behavioral skills including cultural competency. Family medicine educators must be able to assure the public and other constituents that graduates of family medicine residency programs are qualified and competent to provide the full basket of services. Family physicians will continue to face challenges in health care, but they must learn to adapt, to be truly capable lifelong learners, to use new innovations and advances to further patient well-being, and to interact skillfully with every sector of the health care community.

\section{Curriculum Changes}

The family medicine residency curriculum has evolved substantially during the past 3 decades to meet the changing health care needs of the nation and to better 
prepare family physicians to deliver the kind of comprehensive, compassionate, and relationship-based care the public desires. Most curricular elements presently incorporated in family medicine graduate medical education remain pertinent and necessary. Some curricular elements, however, must evolve to remain relevant in a changing environment, new elements must be added to address emerging needs, and new knowledge of educational content delivery and assessment must be incorporated. In addition, longitudinal training elements need to be furthered.

Family physicians must continue to be broadly trained and have the competencies required to provide culturally effective and proficient care in a variety of settings. Specifically, family medicine residency programs must include training in community and population health, maternity care, and the care of hospitalized patients. Although it is important that maternity care continues to be included in the family medicine residency curriculum, training programs must be allowed to tailor that curriculum to be compatible with educational resources and anticipated practices. For example, the Residency Assistance Program criteria for excellence, approved in January 2003, describe 3 levels of maternity care curricula that address differing resources and needs. Similarly, although the care of hospitalized patients must remain an essential component of family medicine residency training, and all family medicine residency graduates must be able to demonstrate competencies in the care of inpatients, some programs might provide more extensive preparation than others.

\section{Vision and Mission for Family Medicine Residency Education}

The recent IOM report, Health Professions Education: A Bridge to Quality, ${ }^{70}$ concludes that health professions education has not kept pace with "changes in patient demographics, patient desires, changing health system expectations, evolving practice requirements and staffing arrangements, new information, a focus on improving quality, or new technologies." The report calls for a new, overarching vision for all health professions education and proposes the following 5 competency areas as the foundation of education: (1) patient-centered care, (2) interdisciplinary team work, (3) evidencebased practice, (4) quality improvement, and (5) informatics. These attributes are central to the new vision of family medicine education. Building on the concepts in the IOM report on health professions education, the vision and mission for family medicine residency education can be stated as follows:

The vision for family medicine residency education is to transform family medicine residency education into an outcome-oriented experience that prepares and develops the family physician of the future to deliver, renew, and function within the New Model of practice and to deliver the best possible care to the American population.

The mission for family medicine residency education is to create a flexible model that trains family physicians to deliver patient-centered care consistently and lead an interdisciplinary team, emphasizing the biopsychosocial model, cultural proficiency, evidencebased practice, quality improvement, informatics, and practice-based research.

\section{Educational Guidelines}

As a visible demonstration of a commitment to these aims and rules, family medicine educators will need to translate them into guidelines for patient care within the medical education system.

Changes in the structure and content of residency programs should be made, as appropriate, to further the goals and values articulated above. Suggested program guidelines include flexibility and responsiveness, innovation and active experimentation, consistency and reliability, individualized to learners' needs and the needs of communities. Program guidelines should also support critical thinking, competency-based education, scholarship and practice-based learning, integration of knowledge, medical informatics, biopsychosocial integration, professionalism, and collaboration and interdisciplinary approaches to learning (Table 7). For example, the discipline should actively experiment with 4 -year residency programs that include additional training to add value to the role of family medicine graduates in the community.

In addition to the above educational guidelines, residency training programs will need to take into consideration several factors.

As health care becomes more complex and medical care becomes more interdependent with other health care services, family physicians of the future will need to be experts at integrating all aspects of care. Given the commitment in family medicine to a biopsychosocial model of care, family physicians will have a special role in promoting better integration of medical and mental health services.

Family physicians will need to learn to work in teams and promote interdisciplinary collaboration in patient care, research, and education. To do so will require special skills in the areas of teamwork, collaboration, organizational management, and leadership.

With growing emphasis on cost resource management and systems-based care, family physicians of the future increasingly will be expected to be adept at weighing population-based and public health considerations in their medical decision making. 


\begin{tabular}{|c|c|}
\hline Guideline & Description \\
\hline Flexibility/responsiveness & Ability to provide education in areas needed to meet geographical and community needs \\
\hline Innovation/active experimentation & $\begin{array}{l}\text { Programs encouraged to try new methods of education, including 4-year curriculum pilot programs, and } \\
\text { to teach the cutting edge of evidence-based medical knowledge }\end{array}$ \\
\hline Consistency/reliability & $\begin{array}{l}\text { Programs provide a basic core of knowledge and produce family physicians who exemplify the values of } \\
\text { the health care system articulated by the Institute of Medicine }\end{array}$ \\
\hline $\begin{array}{l}\text { Individualized to learners' needs } \\
\text { and the needs of the communities } \\
\text { in which they plan to serve }\end{array}$ & $\begin{array}{l}\text { Programs offer enhanced educational opportunities in areas needed by graduates, such as maternity care, } \\
\text { orthopedics, and emergency care }\end{array}$ \\
\hline Supportive of critical thinking & $\begin{array}{l}\text { Programs encourage and/or require research and expect a thorough understanding of evidence-based } \\
\text { medical practice }\end{array}$ \\
\hline Competency-based education & Programs stress a new paradigm for evaluation of resident performance based on competency assessments \\
\hline $\begin{array}{l}\text { Scholarship- and practice-based } \\
\text { learning }\end{array}$ & $\begin{array}{l}\text { Programs integrate scholarship and quality improvement through analysis and interventions built around } \\
\text { patient care activities in the continuity setting }\end{array}$ \\
\hline $\begin{array}{l}\text { Integration of evidence-based and } \\
\text { patient-centered knowledge }\end{array}$ & Programs model knowledge acquisition and processing from both perspectives in the patient care setting \\
\hline Medical informatics & $\begin{array}{l}\text { Programs go beyond just using an electronic health record (EHR) to modeling the broad-based acquisition, } \\
\text { processing, and documentation potential within state-of-the-art informatics resources }\end{array}$ \\
\hline Biopsychosocial integration & $\begin{array}{l}\text { An emphasis on the interdependence and interplay among different levels of the system-whether it is the } \\
\text { cardiovascular system, the individual, the family, the community, or the larger social context }\end{array}$ \\
\hline Professionalism & $\begin{array}{l}\text { Programs move beyond the simple objectives of the Accreditation Council for Graduate Medical } \\
\text { Education professionalism curriculum requirements into a comprehensive monitoring and feedback } \\
\text { system to residents during the critical developmental period of residency training }\end{array}$ \\
\hline $\begin{array}{l}\text { Collaborative and interdisciplinary } \\
\text { approaches to all learning }\end{array}$ & $\begin{array}{l}\text { Programs provide both support and role modeling for the effective use of teams and interdisciplinary } \\
\text { approaches to patient care, including the involvement of other trainees in the process }\end{array}$ \\
\hline
\end{tabular}

The ongoing development of the specialty and its need to contribute more substantially to the body of medical and health systems knowledge will depend on the growth of research and a greater commitment to a culture of ongoing inquiry in family medicine, both in academic and community settings.

To run the family medicine practice of the future efficiently, while adapting to a changing practice environment and striving to deliver optimal patient and population-based care, family physicians will need more in-depth training in practice management, particularly involving electronic health records and other information system applications.

\section{Rearticulating and Redefining the Commitment of Family Medicine to Community and Family} According to the FFM research data, the focus on community by family medicine is one of its best kept secrets. In addition to communicating more effectively the commitment to community and population-based medical care, it is important that family medicine reemphasizes the teaching of community medicine in the broadest terms, devises effective methods to teach community medicine, and identifies metrics by which to evaluate such teaching. In addition, the close connection between family medicine and public health agencies and public health strategies needs to be further strengthened and emphasized.

A seeming paradox is that while the discipline of family medicine places the concept of the family as central to the uniqueness of the discipline, this attribute does not appear to be viewed in this way by many family physicians. For example, in the FFM research only 59\% of family physicians mentioned family as being important in the practice of family medicine. This finding suggests the need to redefine the focus on family in broader terms, because the notion of family is variable and often in flux. Among the implications for residency education is the need to place primary emphasis on the impact of the family on the health of the individual patient and secondary emphasis on treating the entire family unit as patients. Also, residency training should foster increased sensitivity to the wide spectrum of arrangements inherent in the concept of family in current American society, given that many individuals do not consider themselves part of a traditional family unit.

\section{Impact of Changing Demographics}

The changing demographics of the US population, including an aging population, a growing proportion of minorities, and an increasing emphasis on multiculturalism, rather than a melting pot model, present new challenges to family physicians and the health care system as a whole. Family physicians must grapple with issues of cultural differences; variable understandings of and approaches to health, illness, and health care; disparities in health and health care; and special needs of certain populations. Additionally, 
the house of medicine itself is changing, with women and older students making up a growing percentage of the medical student and resident population, and with training institutions continually striving to train and promote more physicians from historically underrepresented minority groups.

Current training models have attempted to address these issues by adding training in cultural competency To meet all the challenges arising out of the changing demographics in the United States, however, family medicine education will need to take a comprehensive approach, integrating behavioral medicine and cultural proficiency into all curricular components, with attention to the special needs of various populations, recruitment and promotion of minority physicians, and systemwide advocacy on behalf of patients.

\section{Residency Education and the New Model of Family Medicine}

The task of designing and implementing a revised model of family medicine residency education is a work in progress. Great opportunities and challenges are associated with creating a new family medicine education model that builds on the experience of the last three decades and prepares family medicine graduates for the future. The key concept, which must be an integral part of whatever new systems are designed, is that the educational process must train family physicians who can function optimally in the New Model practice environment. This environment will require family physicians who are able to humanize medicine by forming intimate, trusting, and long-term relationships with their patients; who understand and practice process-oriented care; who utilize the biopsychosocial model to create satisfying patient-physician relationships with children and adults; who actively measure and strive to improve outcomes; whose practices are driven by information system access to evidencebased principles of care; and who are adaptable to and involved in the creation of relevant new knowledge.

\section{The Role of Medical Education in Enhancing Science and Quality}

Participation in the generation of new knowledge must become integral to the activities of all family physicians and, therefore, should be incorporated into family medicine training. In addition to incorporating practice-based research into the values, structures and processes of family medicine practices, departments of family medicine will be challenged to engage in highly collaborative research that produces new knowledge about the origins of disease and illness, how health is gained and lost, and how the provision of care can be improved. To make such research a reality, a national entity should be established to lead and fund research on the health and health care of whole people.

Related to but distinct from efforts to enhance the science underlying the specialty of family medicine, medical education must also intensify its focus on quality-related issues. To address the quality goals specified in the IOM Chasm Report, close working partnerships must be developed between academic family medicine and communitybased family physicians. In addition, family medicine residency programs should track and report regularly the ongoing performance of their residents on the 6 IOM quality measures and to modify their training programs as necessary to improve performance.

\section{Addressing the Declining Interest in Family Medicine Among Medical Students}

A major challenge facing family medicine is the declining interest in the discipline among medical students. Medical students, who are key to the advancement of family medicine as a discipline, have increasingly been drawn away from the specialty. In 1997 nearly 400 family medicine residency programs across the country attracted 2,340 US medical school (MD) seniors through the National Residency Matching Program, representing 17.3\% of US medical school graduates. In the 2003 match, 1,234 US seniors chose family medicine, a decline of nearly $50 \%$ in a period of only 6 years. ${ }^{71}$

Departments of family medicine must continue to develop, implement, disseminate, and evaluate best practices in expanding student interest in the specialty, including strategies for exposing medical students to the New Model of family medicine, the core attributes and values of family medicine, and the basket of services provided by family physicians.

\section{Comprehensive Family Medicine Career Development Program}

One strategy to increase student interest would be to design and implement a comprehensive family medicine career development program, encompassing elementary through postgraduate education, which would be coordinated across the discipline and involve all major national family medicine organizations. The concept behind this strategy would be to engage family physicians across the country in identifying youth who have the potential to become future family physicians, with the focal point being the science and art of caring that distinguishes the family medicine model.

Through the program, family physicians would strengthen their presence in local school systems, providing health and related education and guidance targeted to students from elementary through high school. Summer and work experiences in the practices of these physicians would reinforce the family medi- 
cine career option as realistic and compelling. Their physician mentors would support their students' college applications.

When these students return home during their college years, they would have an opportunity for credit experiences by performing work or research functions in these same practices. In the process, many would encounter medical students and residents engaged in professional education.

The full-time faculty counterparts of these community physicians (and some community physicians themselves) would simultaneously serve as advocates in the admissions process for these students, whose applications would be strengthened through their experiences and whose ultimate specialty choice would be positively influenced toward family medicine. These students would, in turn, serve as powerful role models for successive generations of students as they progress through medical school and residency, and as they assume leadership positions in their profession and in the community.

\section{Comprehensive Lifelong Learning}

Appropriate design of processes and systems is needed to ensure that all family physicians, regardless of professional role, practice locale, or career stage will continue to deliver the core attributes of family medicine throughout their careers. The best way to accomplish this goal is to develop a comprehensive lifelong learning program for each family physician based on continuous personal, professional, and clinical practice assessment and improvement.

\section{Domains of Management Mastery}

The core attributes of family medicine that must be maintained and enhanced throughout the family physician's career can be organized into a discrete number of general domains. These domains, which are consistent with the domains of the Accreditation Council for Graduate Medical Education and the American Board of Medical Specialties core competencies (medical knowledge, practice-based learning, professionalism, system-based practice, patient care, and interpersonal and communication skills ${ }^{72}$, include the following competencies:

Management of knowledge and information enables the family physician to access information quickly and efficiently, to translate that knowledge effectively in the context of individual patient's needs, and to communicate that information efficiently to patients and colleagues.

Management of relationships requires a continuously improving ability to develop constructive relationships with the patient, members of the patient's family and community, and members of the health care team, consultants, and administrators.

Management and integration of care process allows the family physician to engineer, design, and continuously improve processes of care in all settings in which a family physician may practice, including system design and evaluation skills as well as leadership and management expertise.

Cultural proficiency is essential. As the US population becomes more culturally diverse, family physicians will need to acquire or enhance the skills required to care for patients from diverse cultural, racial, ethnic, economic, and geographic communities.

\section{A Context for Career-Long Learning and Improvement}

Whereas traditional continuing medical education has served to meet many of the original goals for which it was designed, the current model is not adequate to meet the emerging needs of patients, physicians, or health delivery systems. The traditional approach has assumed that once the residency program is completed, a family physician enters a state of personal and professional proficiency requiring only maintenance. In reality, the literature strongly suggests that all professionals, including physicians, continuously develop, grow, and change throughout their careers. ${ }^{73-78}$

Among the suggestions proposed is that developmental processes and stages of a family medicine career be used to generate a foundation for a lifelong learning curriculum. Central to this process is a system to ensure active mentoring of physicians throughout their careers. A developmental approach to a process of continuous personal development is essential to address adequately the personal attributes that are so important in the New Model of family medicine.

This type of developmental approach can be separated into the following 3 components: the development of the family physician as a person, the development of the family physician as a practicing professional, and the development of the family medicine patient care environment as a facilitative environment conducive to improved patient and population outcomes.

\section{The Family Physician as a Person}

An opportunity for reflection and a broader understanding of personal wellness and development should be integral parts of a family physician's practice. Integration into communities of learners will allow family physicians to compare their practices and learn from one another as well as to provide mutual support. A formal process of mentoring should begin during the family medicine residency program and should be maintained throughout the lifetime of a family physician. 
The Family Physician as a Practicing Professional A lifetime curriculum for family physicians should be developed that extends beyond the residency program and continues throughout the course of a family physician's career. This lifetime curriculum should be based on 2 important principles. First, it should be developmental, focused on the most common tasks to be accomplished at each stage of a family physician's career. Second, it should be based on an ongoing system of self-evaluation in which family physicians reflectively evaluate their own professional skills and quality of care in a context that allows them to compare their performance with that of other family physicians and their peers and with guidelines for effective care.

\section{The Family Medicine Patient Care Environment}

Traditionally, continuing medical education has focused on competency and skill development as attributes of physicians. The future viability of family medicine rests in large part on being able to demonstrate the quality of care provided. Accordingly, the process of continuous personal, professional, and clinical practice development implemented as part of the New Model of family medicine should be based on creating practice behavior changes that result in improved patient outcomes and personal productivity. The process for the continual improvement of clinical practice in family medicine must begin with a close working relationship between the academic community and the practice community. This relationship should be iterative, with research creating new practice innovations, which in turn create new questions for research.

\section{Practice Enhancement}

Traditionally, continuing medical education has been measured in contact hours with prescribed or elective credit awarded to family physicians based on time spent in the activity. The goal of continuing education, however, is not simply to improve physician knowledge, but to change physician and practice behavior and thereby improve patient outcomes. What family medicine currently lacks is a process by which practice groups can work together to assess, measure, and improve the quality of care as measured against broadly recognized benchmarks. A system of continuous personal, professional, and clinical practice development based on learning modules completed by practice units or groups can achieve this objective.

The new maintenance of certification process for family physicians requires self assessment using validated, Web-based instruments and patient simulation; a computer-based version of the traditional cognitive examination; and evidence of continuous practice improvement. Physicians will be expected to demon- strate improved patient care through implementation of evidence-based guidelines, meeting performance benchmarks, measuring quality, and improving patient outcomes. This process will be an essential part of the lifelong assessment of family physicians.

\section{Tools for Practice Enhancement}

The following 3 components should be part of the comprehensive practice improvement system that is designed for family medicine: (1) standardized electronic information systems in family medicine offices, as described earlier in this report; (2) a vibrant process of evidence-based review and practice-based research to define the most up-to-date guidelines for clinical practice; and (3) a selfassessment system to allow physicians to receive timely feedback regarding both their personal skills and their practice outcomes in comparison to their peers.

In implementing these practice enhancement tools it will be essential to have an infrastructure to support multipractice improvement efforts, including a network of family medicine offices that can develop and ensure standards of patient care quality and safety. A central concept behind the continuous practice improvement program will be the use of amalgamated data from multiple practices to define questions of importance for improving the care of family medicine patients. The resulting reviews of the medical literature and practice-based research can then be used to develop care guidelines, which will form the foundation of a series of practice improvement modules. Each module will contain tools for self-assessment of the practice, information about the current guidelines and the evidence behind the guidelines, and measurement instruments the practice can use to compare themselves with evidence-based benchmarks in the literature and in reference to best practices in family medicine and primary care. The results of this assessment can then be used as a needs assessment to develop continuous quality improvement projects in the practice and to measure improving patient outcomes.

\section{Recognizing and Enhancing Quality in Practice: A System for Family Medicine}

A process should be developed to reward quality standards for service and ensure the best outcomes of care delivered in participating family medicine practices. One recognition system will be through American Board of Family Practice maintenance of certification for family physicians. Other criteria might include hours of operation, scope of services offered in the practice, and participation of the practice in a modularbased continuous personal, professional, and clinical practice development program, as described above. Participation in such a development curriculum should 
be part of both the certification process for the individual physicians and recognition for the practice.

\section{An Example of the Process at Work}

Assume that a continuous practice improvement module is developed for the care of patients with congestive heart failure. A family medicine group might identify congestive heart failure as an area for self-assessment and practice improvement. The physicians would engage with their office staff and colleagues in the completion of the module. Included in this module would be reading materials, audiovisual materials, and computer-based educational training related to the care and management of patients with congestive heart failure.

These physicians would also generate a registry of patients in their practice who have congestive heart failure and review the care of this patient population to determine the degree to which it is consistent with current guidelines as defined in the module. The audit criteria might include an assessment of which medications these patients are using or which diagnostic tests have been performed. The results of this review would be submitted along with other self-assessment tools to the central facility that provided the module, and the physician and practice self-assessment information would be integrated with the self-assessments from all other practices that have completed this module. A resulting outcome report to the practice would indicate the degree to which the practice is compliant with each of the practice guidelines and compare the practice with its peers. Completion of this module would result in continuing development credits for each of the individual physicians in the practice and might become part of the maintenance of certification process for family physicians.

The accumulated data of all practices completing this self-assessment instrument could serve as an important resource for researchers studying how the quality of care for congestive heart failure can be improved. The final and perhaps most important step in this process is that measurable improvement in the outcomes of patient care would become the reference standard by which continuous personal, professional, and clinical practice development is measured.

\section{BRINGING ABOUT CHANGES IN THE US HEALTH CARE SYSTEM}

Although family medicine can do much to serve the American public through implementation of the New Model of family medicine and through modifications to family medicine education, ultimately broader, systemwide changes will be needed to ensure a strong and vibrant family medicine specialty.

\section{Strategic Priorities}

The FFM Project Leadership Committee believes the US health care system can be improved and transformed by focusing on 6 strategic priorities. Several of these priorities depend primarily on the efforts of family medicine; those priorities will require collaboration with other groups, especially other primary care clinicians, with whom family medicine shares many fundamental objectives. Still other priorities will involve reaching out to multiple, larger audiences. While some family medicine priorities and recommendations are more narrow and targeted than others, they all are intended to heal an ailing US health care system ${ }^{36}$ by stimulating a national conversation and fostering actions that change how Americans think about and use their health care system.

The 6 priorities for health system reform identified by the Project Leadership Committee are as follows:

1. Taking steps to ensure every American has a personal medical home

2. Advocating that every American have health care coverage for basic services and protection against extraordinary health care costs

3. Promoting the use and reporting of quality measures to improve performance and service

4. Advancing research that supports the clinical decision making of family physicians and other primary care clinicians

5. Developing reimbursement models to sustain family medicine and primary care practices

6. Asserting family medicine's leadership to help transform the US health care system

\section{Taking Steps to Ensure Every American}

\section{Has a Personal Medical Home}

FFM research found that only about $15 \%$ of Americans want to go it alone in health care; most prefer an ongoing relationship with a personal physician. ${ }^{44}$ The Project Leadership Committee believes that the concept of a personal medical home will have considerable appeal for Americans and is of great importance for high-quality effective health care. The medical home, as proposed, can serve as the focal point for an individual's health care, providing care that is accessible, accountable, comprehensive, integrated, and patient-centered.

Accessible means that services are accessible financially (affordable, with all payers participating), geographically (near home or work), and temporally (available 24 hours a day, 7 days a week). Accountable means that a medical home provides and reports service that meets or exceeds quality standards. Comprehensive means that the medical home offers a wide range of services, including health education and promotion, preventive services, evaluation and management of 
the undifferentiated complaint, care of both acute and chronic conditions, end-of-life care, and referral to other clinicians as appropriate. Integrated means that the medical home serves as the usual entry point for health care, develops a care plan for each individual, maintains a comprehensive and confidential health record for each individual, and integrates care across all professionals (eg, consultants) and all settings (eg, home, hospital, extended care facility, office). Patient centered means that the medical home provides services that are empathic, respectful, and culturally effective.

Americans value choice. At the same time, studies show that care organized around a primary care relationship results in better outcomes at lower cost. ${ }^{79-82}$ Incentives can be developed that will allow Americans to choose the kind of health care they want, but at a price that reflects the effectiveness and efficiency of the model they choose. Individuals should be able to choose or change their medical home through an easy and well-defined process. Maintaining a continuous relationship with an identified personal medical home should be supported. A standard health care covenant should describe explicitly the mutual expectations of the individual and the medical home.

Implementation of the medical home concept will depend on changes in medical education and health care funding and organization so that trainees and clinicians will be attracted in sufficient numbers to primary care to meet the workforce needs associated with this recommendation. In addition, efforts to enhance health literacy among patients will need to be initiated (including an information campaign on the benefits of having a personal medical home), and standards for an electronic health record will need to be developed that promote the use of a personal medical home and encourage research in practice improvement.

\section{Ensuring Health Care Coverage for All Americans} Reform of the funding of American health care is an essential part of the healing of the ailing system. The lack of health care coverage for all in the United States results in inequities and inefficiencies that can no longer be sustained and should no longer be tolerated. It is essential that every American have health care coverage that assures adequate funding of basic health care services and protection against extraordinary health care costs. Once the goal of health care coverage for everyone is accomplished, tools will need to be developed to help patients make informed decisions about a personal medical home and health care coverage. Family medicine will need to exercise a leadership role both in advocating for heath care coverage for all and in helping patients appropriately access health care services.
Promoting the Use and Reporting of Quality Measures Quality has proved to be a challenging notion in health care. Although it is universally desired and most people recognize it when they experience it, there has been limited resolve to develop agreement on, funding of, and measures for quality. Quality includes measures of outcomes that patients care about (death, discomfort, disability), as well as customer service and costs. Quality measurement, driven in part by the patient safety movement, is gaining momentum and will be an enduring challenge and opportunity for health care. As a first step toward accomplishing this priority, family medicine should develop and begin reporting regularly for all family physicians their performance on at least one measure for each of the IOM 6 aims of high-quality health care: safe, timely, effective, equitable, patientcentered, and efficient. These measures should assess quality at the level of the whole person rather than individual disease states and should account for patient values and priorities.

With time, academic organizations, such as the Residency Review Committee for family medicine, should be expected to tie residency program accreditation to acceptable performance by residency graduates. Family medicine residencies would be expected to track and report regularly the performance of their residents during their training against the 6 measures and modify their training programs to improve the performance of their graduates.

\section{Advancing Research Supporting the Integrated Care of the Whole Person}

Clinical research traditionally has been conducted in academic medical centers, which comprise a very small and atypical representation of American patients and medical practice. Thus, federally funded research has had an uneven and inadequate impact on clinical practice. Better balance in research priorities and funding is needed to assure that generalist clinicians have answers to the questions they confront in daily practice. Research is an essential component of quality and continuous improvement and should be woven into every practice. Government funding agencies, foundations, health plans, and others should promote research by and for family physicians and other primary care clinicians as a long-term investment to enhance patient care and health system improvement. The AAFP has shown considerable leadership through its Research Initiative and the nearly $\$ 8$ million that has been invested during the past 5 years to stimulate and support research in the discipline. Sustainable sources of noncategorical funding are needed, however, to support whole-person primary care research.

It is time for the research needs of family medicine 
and primary care to be placed on an equal footing with the rest of medicine. The great disparity in federal funding for primary care research compared with research funding for the rest of medicine has meant that important questions raised by the clinicians who provide most of the medical care in the United States go unexamined and unanswered. An entity should be established to foster, coordinate, and fund research in family medicine and primary care. A communications network for primary care clinicians should be created to enable them to share data, answer questions, and solve problems that are broad based and relevant. Practice-based research networks and sentinel practice systems are examples of such networks. Because funding drives research priorities, funding should be developed to encourage academic and other institutions to pursue research on the value of a personal medical home and an integrative, generalist approach to health.

\section{Developing Reimbursement Models to Sustain Family Medicine and Primary Care}

The current reimbursement system for primary care practices is not sustainable. Practice resources are insufficient in the current system to accomplish many of the tasks essential for an improved and transformed health care system (eg, a personal medical home for every American, electronic health records, quality monitoring and reporting). Specific recommendations regarding reimbursement and financial models for the practices of family physicians are being developed by a newly formed FFM task force, which is expected to report its findings and recommendations in late 2004.

\section{Asserting Family Medicine's Leadership to Help Transform the Health Care System}

Leadership can and must be identified, nurtured, and supported. Investment of resources and cultivation of talent will be needed for such leaders to emerge. The FFM Project Leadership Committee believes it is vitally important to groom leaders within family medicine who will change the health care landscape and to create venues where policy makers and influence leaders can look beyond their usual constituencies and horizons to a comprehensive view of health care.

Specific steps that should be pursued in furtherance of these objectives include (1) targeting a few major policy initiatives and using a multipronged approach for their implementation; (2) convening a summit of primary care leaders as a step toward a stronger and more unified voice within primary care ${ }_{i}$ (3) organizing a leadership center for family medicine and primary care to serve as a focal point for cross-disciplinary research on effective leadership strategies, to coordinate leadership development and advocacy efforts, and to cultivate resources for leadership programs and research; (4) promoting family physicians and other primary care advocates as leaders in their communities, in government, and in other influential groups; and (5) convening a blue-ribbon panel of key stakeholders from advocacy groups, business, government, health care professionals, health-related industries, health plans, and labor to address comprehensive health system reform and to articulate a compelling vision for health care in America.

\section{Addressing the Challenges Involving Academic Health Centers}

In addition to pursuing the 6 strategic priorities discussed above, family medicine faces the challenge of redefining the relationship of family medicine to and its role within the academic health center (AHC). Undoubtedly, AHCs occupy a special niche in American health care and deserve much credit for the successes of the US health care system. They train a considerable portion of health care professionals, conduct important research, and provide substantial amounts of clinical care. Indeed, many advances in health care can be traced directly to the work done in AHCs.

At the same time, AHCs contribute to many of the failings of the US health care system. The concentration of resources by AHCs on ever narrower areas of inquiry and the proliferation of investigators and clinicians that flow from those areas reflect $\mathrm{AHC}$ priorities that typically value cure rather than prevention, subspecialization rather than generalism, fragmentation of care rather than integration, and career advancement rather than community responsiveness. The prominence of AHCs and the many physicians they produce have resulted in the values of AHCs dominating the values of US medicine.

With the emphasis of family medicine on prevention, generalism, integrated care, and community, it is not surprising that the culture of family medicine is often seen as incongruent with the culture of AHCs. Despite more than 3 decades of effort, AHCs continue to be regarded by some as a challenging environment for family medicine. Recent studies affirm that the medical school environment disproportionately disparages family medicine, even when compared with other primary care disciplines. ${ }^{83}$

Many family medicine departments have not always articulated their full value in furthering the clinical, educational, and research missions of the AHCs. Family medicine faculties are more likely to be consumed by the demands of clinical care and teaching, with little time, energy, motivation, or resources for scholarly inquiry. As the discipline matures, family medicine is challenged by the need to decide what role it should 
play in academic medicine. This time is also opportune for AHCs and family medicine to reexamine their respective agendas and to commit to a shared future around common goals.

A starting point in this process would be to organize a summit of policy makers and academic and practicing family medicine leaders to review the role of, and make recommendations on, the future of family medicine in academia. Such a summit could explore such issues as enhancing the standing of family medicine within $\mathrm{AHCs}$, developing mentoring and leadership development programs for family physicians, funding family medicine research and academic development, addressing issues in the IOM report on academic health centers relating to primary care, and identifying strategies to reverse the declining student interest in family medicine as a career.

\section{MOVING FORWARD: THE LEADERSHIP AND COMMUNICATION CHALLENGE}

The leadership and communication challenge facing family medicine can be aptly described as family physicians and the process of change-Leading who? To what? How? Those identified as "who" comprise the various audiences for the leadership and communication efforts of family medicine. Depending on the issue involved, some audiences represent potential allies; at other times, they represent potential adversaries. Target audiences include family physicians, other primary care physicians (ie, general internists and general pediatricians), other physicians and health care professionals, medical students, government and other purchasers of health care, the public, patients, and consumer groups, medical and health professional organizations, health plans, employer and labor groups, and governmental and nongovernmental policy makers.

The "what" signifies the key elements, or strategic priorities, to achieve the compelling vision for family medicine and the US health care system. In establishing strategic priorities for family medicine, the following should be the overriding principle: that health system change should be patient centered, relationship based, quality focused, and team oriented. Whereas the focus of the FFM project has been to identify ways in which family medicine should create change, it is important to recommend change that will reflect patient values, strengthen the patient-physician relationship, assure the quality and competence of the care provided, and reinforce a commitment to working in the context of health care teams.

The "how" points toward specific strategies to accomplish the agreed-upon priorities. The audiences and the tactics will vary depending on the strategic priority involved. For example, achieving the recommendation that every American have a personal medical home could easily involve all the target audiences, with a different tactic for each. Successful implementation of another recommendation in this report - that a leadership center for family medicine and primary care be created-would likely involve a select few audiences (eg, family physicians, other primary care physicians, and professional organizations of primary care physicians), with specific, targeted strategies for each.

One important conclusion from the FFM research data is that, as a discipline, family medicine has yet to formulate and deliver a compelling message. In carrying forward the recommendations of this report, it will be critical to address the target audiences in terms they understand and care about and in ways that convey a sense of the exciting and rewarding roles that family physicians will assume in the future.

It is particularly important that 2 audiences get this message: family physicians and medical students. Family physicians are a primary audience for the message regarding the New Model of family medicine. Their understanding, involvement, and personification of these changes are central to transforming the discipline. Medical students, however, represent the future. Family medicine, to be successful, must stimulate interest among students through a commitment to a promising patient-centered future.

A major strength of family medicine is its local adaptability, which has resulted in considerable heterogeneity within the discipline. Because of the diversity among family physicians in terms of scope of services, practice location, practice arrangements, demographic characteristics of the patient population, and financial attributes of the practice, the development of communication strategies will be challenging. Few messages will resonate with all family physicians, so there must be a variety of messages that take into account the widely varying circumstances in which family physicians practice medicine.

Regardless of the specific messages, it will be important to emphasize the many benefits and opportunities presented by the New Model of family medicine, including positive, rewarding relationships with patients; intellectual stimulation; a role in truly integrating patient care; an opportunity to work in multidisciplinary teams; an opportunity to provide effective practice administration, to communicate with patients, and to network with other practices; an opportunity to make a difference in the lives of patients, their families, and the community; a role in generating relevant new knowledge through practice-based research; and the 
chance to use new information technology to deliver and improve care.

Effective leadership is an essential ingredient that will determine, to a large extent, the success of family medicine in advocating for changes within the specialty and in the health care system overall. By understanding the needs of those they serve, by helping to shape a compelling vision for a better system, and by working in concert with the many individuals whose lives they touch, family physicians offer the best hope for transforming the health care system.

Advocacy in pursuit of the New Model of family medicine, a reordering of health care priorities, and a shift in the traditional medical paradigm in the United States pose a risk for the discipline of family medicine. Having labored mightily to gain entry into academia, family medicine has determined that the structure needs major renovation. Challenging the status quo means that family physician leaders may risk the disapproval of their colleagues and those with a vested interest in the current system. Now, however, is the time for action. Family physicians are well suited for leadership as they interface with the whole system. Nothing less than the health of the American public is at stake.

The extensive research and analyses conducted as part of this study provide a better understanding of the essential building blocks for a more effective, modern family medicine specialty that will assume its rightful role in enhancing the health and health care of all Americans. The challenge now facing family medicine is to take the initiative for change, engage others truly committed to reform, and to see the process through — in all of its complexities and risks-to a successful conclusion.

\section{RECOMMENDATIONS}

Family physicians are committed to fostering health and integrating health care for the whole person by humanizing medicine and providing science-based, high-quality care. To remain true to this statement of identity, while continuing to meet the needs of patients and society in a changing health care environment, family medicine must promote innovation in the delivery of clinical services and in the education of clinicians. In addition, family physicians and their organizations must seek out and partner with those who share similar values and a commitment to innovation and transformation of the US health care system. The following recommendations, which represent a compilation of major recommendations from the Future of Family Medicine task forces, are intended to provide a framework to guide a period of active experimentation and innovation within the discipline.

\section{New Model of Family Medicine}

Family medicine will redesign the work and workplaces of family physicians. This redesign will foster a New Model of care based on the concept of a relationshipcentered personal medical home, which serves as the focal point through which all individuals-regardless of age, gender, race, ethnicity, or socioeconomic status participate in health care. In this new medical home, patients receive a basket of acute, chronic, and preventive medical care services that are accessible, accountable, comprehensive, integrated, patient-centered, safe, scientifically valid, and satisfying to both patients and their physicians. This New Model will include technologies that enhance diagnosis and treatment for a large portion of problems that patients bring to their family physicians. Business plans and reimbursement models will be developed to enable the reengineered practices of family physicians to thrive as personal medical homes, and resources will be developed to help patients make informed decisions about choosing a personal medical home. A financially self-sustaining national resource will be implemented to provide practices with ongoing support in the transition to the New Model of family medicine.

\section{Electronic Health Records}

Electronic health records that meet standards which support the New Model of family medicine will be implemented. The electronic health record will enhance and integrate communication, diagnosis and treatment, measurement of processes and results, analysis of the effects of comorbidity, recording and coding elements of whole-person care, and promoting ongoing healing relationships between family physicians and their patients.

\section{Family Medicine Education}

Family medicine will oversee the training of family physicians who are committed to excellence, steeped in the core values of the discipline, expert in providing family medicine's basket of services within the New Model of family medicine, skilled at adapting to varying patient and community needs, and prepared to embrace new evidence-based technologies. Family medicine education will continue to include training in maternity care, the care of hospitalized patients, community and population health, and culturally effective and proficient care. Innovation in family medicine 
residency programs will be supported by the Residency Review Committee for Family Practice through 5 to 10 years of curricular flexibility to permit active experimentation and ongoing critical evaluation of competency-based education, expanded training programs, and other strategies to prepare graduates for the New Model. In preparation for this process, every family medicine residency will implement electronic health records by 2006 .

\section{Lifelong Learning}

The discipline of family medicine will develop a comprehensive, lifelong learning program. This program will provide the tools for each family physician to create a continuous personal, professional, and clinical practice assessment and improvement plan that supports a succession of career stages. This personalized learning and professional development will include self-assessment and learning modules directed at individual physicians and group practices that incorporate science-based knowledge into educational interventions fostering improved patient outcomes. Family medicine residency programs and departments will incorporate continuing professional development into their curricula and will initiate and model the support process for lifelong learning and maintenance of certification.

\section{Enhancing the Science of Family Medicine}

Participation in the generation of new knowledge will be integral to the activities of all family physicians and will be incorporated into family medicine training. Practice-based research will be integrated into the values, structures, and processes of family medicine practices. Departments of family medicine will engage in highly collaborative research that produces new knowledge about the origins of disease and illness, how health is gained and lost, and how the provision of care can be improved. A national entity should be established to lead and fund research on the health and health care of whole people. Funding for the Agency for Healthcare Research and Quality should be increased to at least $\$ 1$ billion per year.

\section{Quality of Care}

Close working partnerships will be developed between academic family medicine, community-based family physicians, and other partners to address the quality goals specified in the IOM Chasm Report. Family physicians and their practice partners will have support systems to measure and report regularly their performance on the 6 IOM aims of high-quality health care (safe, timely, effective, equitable, patient-centered, and efficient). Family medicine residency programs will track and report regularly the performance of their residents during their train- ing on the 6 IOM quality measures and will modify their training programs as necessary to improve performance.

\section{Role of Family Medicine in Academic Health Centers}

Departments of family medicine will individually and collectively analyze their position within the academic health center setting and will take steps to enhance their contribution to the advancement and rejuvenation of the academic health center to meet the needs of the American people. A summit of policy makers and family medicine leaders in academia and private practice will be convened to review the role of and make recommendations on the future of family medicine in academia.

\section{Promoting A Sufficient Family Medicine Workforce}

A comprehensive family medicine career development program and other strategies will be implemented to recruit and train a culturally diverse family physician workforce that meets the needs of the evolving US population for integrated health care for whole people, families, and communities. Departments of family medicine will continue to develop, implement, disseminate, and evaluate best practices in expanding student interest in the specialty.

\section{Communications}

A unified communications strategy will be developed to promote an awareness and understanding of the New Model of family medicine and the concept of the personal medical home. As part of this strategy, a new symbol for family physicians will be created, and consistent terminology will be established for the specialty, including use of family medicine rather than family practice and family physician rather than family practitioner. In addition, a system will be developed to communicate and implement best practices within family medicine.

\section{Leadership and Advocacy}

A leadership center for family medicine and primary care will be established, which will develop strategies to promote family physicians and other primary care physicians as health policy and research leaders in their communities, in government, and in other influential groups. In their capacity as leaders, family physicians will convene leaders to identify and develop implementation strategies for several major policy initiatives, including assuring that every American has access to basic health care services. Family physicians will partner with others at the local, state, and national levels to engage patients, clinicians, and payers in advocating for a redesigned system of integrated, personalized, equitable, and sustainable health care. 
To read or post commentaries in response to this article, see it online at http://www.annfammed.org/cgi/content/full/2/suppl_1/S3.

Funding support: The Future of Family Medicine project is supported by the following family medicine organizations: American Academy of Family Physicians (AAFP), American Academy of Family Physicians Foundation (AAFPF), American Board of Family Practice (ABFP), Association of Departments of Family Medicine (ADFM), Association of Family Practice Residency Directors (AFPRD), North American Primary Care Research Group (NAPCRG), and Society of Teachers of Family Medicine (STFM). Major support has been contributed by Eli Lilly Foundation; Pharmacia, Pharmacia Foundation; Pfizer, Pfizer Foundation; and the Robert Wood Johnson Foundation. In addition, generous support has been obtained from the Health Resources and Services Administration, Schering-Plough Corporation, and Wyeth Pharmaceuticals.

Acknowledgment: Special thanks are extended to members of the Family Medicine Working Party, who provided guidance and direction to the Project Leadership Committee.

Future of Family Medicine Research Advisory Committee: John R. Bucholtz, DO; John C. Dickinson, MD; Larry A. Green, MD; Warren A. Jones, MD, FAAFP; James C. Martin, MD, FAAFP; Richard G. Roberts, MD, JD; Kurt C. Stange, MD, PhD.

Future of Family Medicine Project Staff: Norman B. Kahn, Jr, MD, FFM Staff Executive; Sarah Thomas, Assistant Staff Executive; Marilyn A. McMillen, MBA, Project Manager; Dorothy Young, FFM Administrative Assistant; Nina Carnoali, FFM Staff Assistant; Ruth Coram, FFM Staff Assistant.

\section{Task Force Members}

Task Force 1: Larry A. Green, MD, Chair; Stephen P. Bogdewic, PhD, Vice Chair; Bruce Bagley, MD; Stephen C. Crane, PhD, MPH; William Jackson Epperson, MD, MBA; Julea Garner, MD; Robert Graham, MD; Cal Gutkin, MD; William Kane, MD; Charles M. Kilo, MD, MPH; Jeannette South-Paul, MD; Stephen J. Spann, MD; John Swanson, MPH; David Kibbe, MD.

Task Force 2: John R. Bucholtz, DO, Chair; Samuel C. Matheny, MD, MPH, Vice Chair; John C. Anderson, MD; Diane Kaye Beebe, MD; Erika B. Bliss, MD; Alan David, MD; Elizabeth Garrett, MD, MSPH; Deborah G. Haynes, MD; Bruce E. Johnson, MD; Eliana C. Korin, Dipl Psic; Sandra Mendez, MD; James E. Zini, DO; Perry A. Pugno, MD, MPH, CPE; Pamela Williams.

Task Force 3: Warren A. Jones, MD, Chair; Robert F. Avant, MD, Vice Chair; Robert D. Fox, EdD; Timothy Komoto, MD; Murray Kopelow, MD, MS, FRCPC; David Loxtercamp, MD; Paul Lyons, MD; Michael L. McBrearty, MD; Paul V. Miles, MD; Dennis E. Richling, MD; John Saultz, MD; Susan Schooley, MD; Nancy Davis, PhD; Deborah S. McPherson, MD.

Task Force 4: John C. Dickinson, MD, Chair; Kenneth L. Evans, MD, Vice Chair; Thomas R. Berry, PA-C, MBA; Carla Cesario; Joel Feigin, MD; Carole Feld; Tristan Guevara, DO; Beulette Y. Hooks, MD; Mike Magee, MD; Lee Newcomer, MD; Joseph E. Scherger, MD, MPH; Michael Scotti, MD; Jan Carter, MBA; Cynthia Stapp.

Task Force 5: Richard G. Roberts, MD, JD, Chair; Pam S. Snape, MD, Vice Chair; Beverly E. Aist, MD; Errol Alden, MD; Maggie Blackburn, MD; Paul C. Brucker, MD; Neil Stephen Calman, MD; Nancy Dickey, MD; Ann C. Jobe, MD, MSN; Jean K. Johnson, RN-C, PhD; Walter McDonald, MD; David Satcher, MD, PhD; Kevin Burke.

\section{Task Force Reactor Panels}

Task Force 1: Kara Cadwallader, MD; Douglas Campos-Outcalt, MD, MPA; Don Cauthen, MD; Jennifer DeVoe, MD, DPhil; Mark Ebell, MD, MS; Kevin Grumbach, MD; Steven Lawenda, MD; Paul Nutting, MD, MSPH; Frank Reed, MD; Lee Sacks, MD; Bertha Safford, MD; Terrence Steyer, MD; Michael Temporal, MD; George H. White, MD.

Task Force 2: Diane Kaye Beebe, MD; Gregory H. Blake, MD; Richard Boothe II, MD; Richard Brunader, MD; Colleen Conry, MD; Samuel W. Cullison, MD; Alan K. David, MD; Charles E. Driscoll, MD; Ted Epperly, MD; Roxanne Fahrenwald, MD; Warren Heffron, MD; Terrence M. Leigh, EdD; Nancy Pandhi, MD; Perry A. Pugno, MD, MPH, CPE; James Puffer, MD; Mary Elizabeth Roth, MD; John W. Saultz, MD; Susan Schooley, MD; J. Lewis Sigmon, Jr, MD; Cynthia W. Weber, MA; Mary E. Willard, MD.

Task Force 3: Stoney Abercrombie, MD; Thomas Bent, MD; Craig W. Czarsty, MD; John Fogarty, MD; Larry A. Green, MD, Scott Kirsch, MD; E. John Lentini, DO; Abdul Nayeem, MD; D. Dean Patton, MD; Perry A. Pugno, MD, MPH, CPE; Susan Rife, DO; George W. Shannon, MD.

Task Force 5: James Bentley; Judy Chamberlain, MD; Stephen C. Crane, PhD, MPH; Bob Crittenden, MD; Carol C. Diamond, MD, MPH; Michael Fine, MD; John Geyman, MD; Charles Inlander; Virgilio Licona, MD; John Little; Alma Littles, MD; Mike Magee, MD; Fitzhugh Mullan, MD; Lee Newcomer, MD; Ed O'Neil; Mike Rosenthal, MD; Thomas Rosenthal, MD; Robert Schiller; Rosemary A. Stevens, MPH; Linda J. Stierle, MSN, RN, CNAA; Sheila Tate; Greg Thomas; Bruce Soloway, MD.

\section{References}

1. Citizens Commission on Graduate Medical Education. The Graduate Education of Physicians: The Report of the Citizens Commission on Graduate Medical Education. Chicago, IL: American Medical Association; 1966.

2. American Medical Association. Ad Hoc Committee on Education for Family Practice. Meeting the Challenge of Family Practice: The Report of the Ad Hoc Committee on Education for Family Practice of the Council on Medical Education. Chicago, IL: American Medical Association; 1966.

3. Graham R, Roberts RG, Ostergaard DJ, Kahn NB, Pugno PA, Green LA. Family practice in the United States. A status report. JAMA. 2002;288:1097-1101.

4. Kitzhaber J. The road to meaningful reform: a conversation with Oregon's John Kitzhaber. Interview by Jeff Goldsmith. Health Aff (Millwood). 2003;22:114-124.

5. Wilensky G. Thinking outside the box? A conversation with John Breaux. Health Aff (Millwood) [serial online]. 2003;22:15. Available at: http://content. healthaffairs. org/cgi/reprint/hlthaff.w3.124v1.pdf.

6. David AK. Necessary change in family medicine: entering adulthood. Fam Med. 2003;35:217-219.

7. Geyman JP. Family practice in a failing health care system: new opportunities to advocate for system reform. J Am Board Fam Pract. 2002:15:407-416

8. Sox HC. The future of primary care. Ann Int Med. 2003;4:230-232.

9. Berwick DM. Public performance reports and the will for change. JAMA. 2002;288:1523-1524.

10. Avant RR. Family practice: exclusive, inclusive, or-heaven forbidboth? J Am Board Fam Pract. 2002;15:506-508.

11. Edsall RL. Recreating family practice. Fam Pract Manage. 2002:9:10.

12. Holahan J, Pohl MB. Changes in insurance coverage: 1994-2000 and beyond. Health Aff (Millwood). 2002;Supp Web Exclusives: W162-171.

13. Zuvekas SH, Taliaferro GS. Pathways to access: health insurance, the health care delivery system, and racial/ethnic disparities, 1996-1999. Health Aff (Millwood). 2003;22:139-153. 
14. Institute of Medicine. Committee on the Consequences of Uninsurance. Care Without Coverage: Too Little, Too Late. Institute of Medicine. Washington DC: National Academy Press; 2002.

15. Fee $E$, Brown TM. The unfulfilled promise of public health: déjà vu all over again. Health Aff (Millwood). 2002;21:31-43.

16. Institute of Medicine. Committee on Assuring the Health of the Public in the 21st Century. The Future of the Public's Health in the 21st Century. Institute of Medicine. Washington DC: National Academy Press; 2002.

17. Mechanic D, McAlpine DD. Mission unfulfilled: potholes on the road to mental health parity. Health Aff (Millwood). 1999;18:7-21.

18. Iglehart J. The woeful neglect of health care workforce issues. Health Aff (Millwood). 2002;21:7-8

19. Grumbach K. Fighting hand to hand over physician workforce policy. Health Aff (Millwood). 2002;21:13-27.

20. Reinhardt UE. Dreaming the American dream: once more around on physician workforce policy. Health Aff (Millwood). 2002;21:28-32.

21. Masys DR. Effects of current and future information technologies on the health care workforce. Health Aff (Millwood). 2002;21:33-41.

22. Ward D, Berkowitz B. Arching the flood: how to bridge the gap between nursing schools and hospitals. Health Aff (Millwood). 2002;21:42-52

23. Mertz $\mathrm{E}, \mathrm{O}^{\prime} \mathrm{Neil} \mathrm{E}$. The growing challenge of providing oral health care services to all Americans. Health Aff (Millwood). 2002;21:65-77.

24. Kovner CT, Mezey M, Harrington C. Who cares for older adults? Workforce implications of an aging society. Health Aff (Millwood). 2002;21:78-89.

25. Cohen JJ, Gabriel BA, Terrell C. The case for diversity in the health care workforce. Health Aff (Millwood). 2002;21:90-102.

26. Phillips RL, Harper DC, Wakefield M, Green LA, Fryer GE. Can nurse practitioners and physicians beat parochialism into plowshares? Health Aff (Millwood). 2002;21:133-142.

27. Smedley BD, Stith AY, Nelson AR. Institute of Medicine. Committee on Understanding and Eliminating Racial and Ethnic Disparities in Health Care. Unequal Treatment: What Health Care Providers Need to Know About Racial and Ethnic Disparities in Health Care. Institute of Medicine. Washington DC: National Academy Press; 2003.

28. Kohn LT, Corrigan J, Donaldson MS. Institute of Medicine. Committee on Quality of Health Care in America. To Err Is Human. Building a Safer Health System. Institute of Medicine. Washington DC: National Academy Press; 2000.

29. Robert Graham Center. Toxic cascades: a comprehensive way to think about medical errors. Am Fam Physician. 2001;63:847.

30. Levit K, Smith C, Cowan, C, Lazenby H, Sensenig A, Catlin A. Trends in US health care spending, 2001. Health Aff (Millwood). 2003;22: 154-164.

31. Watts C, Christianson JB, Heineccius L. Trude S. The role of public employers in a changing health care market. Health Aff (Millwood). 2003; 22:173-180.

32. Ramminger S. Care Last. My son is a pawn in the battle between hospital and health insurer. Washington Post Outlook. January 5 , 2003;B8.

33. Lieberman T. Bruised and broken: US health system. AARP Bulletin. March 2003; 44:1-5.

34. Broder DS. Health care hopes. Washington Post Outlook. March 16 2003;B7.

35. Flocke SA, Stange KC, Zyzanski SJ. The impact of insurance type and forced discontinuity on the delivery of primary of care. J Fam Pract. 1997;45:129-135.

36. Geyman JP. Health Care in America. Can Our Ailing System Be Healed? Boston, Mass: Butterworth-Heinemann; 2002.
37. Reed M, Ginsburg PB. Behind the times: physician income, 19951999. Data Bulletin No.24. Results from HSC Research Number 24, March 2003. Available at: http://www.hschange.org/CONTENT/544.

38. Donaldson MS, Yordy KD, Lohr KN, Vanselow NA, eds. Committee on the Future of Primary Care Services. Institute of Medicine. Primary Care. America's Health in a New Era. Washington, DC: National Academy Press; 1996.

39. Starfield B. Primary Care: Concept, Evaluation, and Policy. New York, NY: Oxford University Press; 1992.

40. Pugno PA, McPherson DS, Schmittling GT, Kahn NB Jr. Results of the 2002 National Resident Matching Program: family practice. Fam Med. 2002:34:584-591.

41. Institute of Medicine. Committee on Quality of Health Care in America. Crossing the Quality Chasm: A New Health System for the 21st Century. Institute of Medicine. Washington DC: National Academy Press; 2001

42. Green LA, Fryer GE Jr. Family practice in the United States: position and prospects. Acad Med. 2002;77:781-789.

43. Green LA, Graham R, Frey JJ, Stephens GG, eds. Keystone III. The Role of Family Practice in a Changing Health Care Environment: A Dialogue. Washington, DC: American Academy of Family Physicians; 2001.

44. Family Practice Working Party and Academic Family Medicine Organizations. Future of Family Medicine [FFM Web site]. Available at http://www.futurefamilymed.org. Accessed April 4, 2003.

45. Greenfield S, Nelson ED, Zubkoff $M$, et al. Variations in resource utilization among medical specialties and systems of care. JAMA. $1992 ; 267: 1624-1630$

46. Greenfield S, Rogers W, Mangotich M, Carney MF, Tarlov AR. Outcomes of patients with hypertension and non-insulin-dependent diabetes mellitus treated by different systems and specialties: results from the Medical Outcomes Study. JAMA. 1995;274:1436-1444.

47. World Health Organization. The world health report 2003: shaping the future. 2003. Available at: http://www.who.int/whr/en/.

48. Green LA, Fryer GE Jr, Yawn BP, Lanier D, Dovey SM. The ecology of medical care revisited. $N$ Engl J Med. 2001;344:2021-2025.

49. Starfield B, Lemke KW, Bernhardt T, Foldes SS, Forrest CB, Weiner JP. Comorbidity: implications for the importance of primary care in "case" management. Ann Fam Med. 2003;1:8-14.

50. Center for Disease Control and Prevention. National Center for Health Statistics. Ambulatory Health Care Data: National Ambulatory Medical Care Survey (NAMCS). Hyattsville, Md: National Center for Health Statistics. US Public Health Service; 2002. Available at: http: //www.cdc.gov/nchs/about/major/ahcd/ahcd1.htm.

51. Biola H, Green LA, Phillips RL, Guirguis-Blake J, Fryer GE, for the Robert Graham Center. The US primary care physician workforce: undervalued service. Am Fam Physician. 2003;68:1486.

52. Stange KC, Jaen CR, Flocke SA, Miller WL, Crabtree BF, Zyzanski SJ. The value of a family physician. J Fam Pract. 1998;46:363-368.

53. Wennberg JE. Unwarranted variation in healthcare delivery: implications for academic medical centres. BMJ. 2002;325:961-964.

54. Frey JJ and Saultz JW. Academic family medicine. In: Saultz JW. Textbook of Family Medicine: Defining and Examining the Discipline. New York, NY: McGraw-Hill; 2000:chap 57

55. Alpert JJ, Charney E. The Education of Physicians for Primary Care. Washington, DC: US Department of Health, Education, and Welfare; 1973. Publication HRA 74-3113.

56. McWhinney IR. William Pickles Lecture 1996. The importance of being different. Brit J Gen Pract. 1996;46:433-436.

57. Coulter A. Patients' views of the good doctor. BMJ. 2002;325:668-669.

58. Main DS, Tressler C, Staudenmaier A, Nearing KA, Westfall JM, Silverstein M. Patient perspectives on the doctor of the future. Fam Med. 2002;34:251-257. 
59. Lawrence DM. My mother and the medical care ad-hoc-racy. Health Aff (Millwood). 2003;22:238-242.

60. Morgenstern L. A piece of my mind. Will the real doctor please stand up? JAMA. 2003;289:18.

61. Institute for Healthcare Improvement. QualityHealthCare.org Web site. Available at http://www.QualityHealthCare.org.

62. Aluise JJ. The Physician as Manager. Bowie, MD: Charles Press; 1980

63. Schooley S. Family physicians in management. In: Saultz JW. Textbook of Family Medicine: Defining and Examining the Discipline. New York, NY: McGraw-Hill; 2000:chap 58.

64. Bates DW, Ebell M, Gotlieb E, Zapp J, Mullins HC. A proposal for electronic medical records in U.S. primary care. J Am Med Inform Assoc. 2003;10:1-10.

65. Lindberg W. Consumer representation in health services delivery consumers and guidelines: how to involve consumers in the development of best-practice guidelines. Healthcare Review - Online. 1999:3: 5. Available at: http://www.enigma.co.nz/hcro/website/index.cfm?fuse action $=$ articledisplayEFeatureID =76. Accessed May 5, 2003.

66. American Hospital Association Commission on Workforce for Hospitals and Health System. In Our Hands: How Hospital Leaders Can Build a Thriving Workforce. Chicago, Ill: American Hospital Association; 2002.

67. Crane SC. Trends in care by nonphysician clinicians. N Engl J Med. 2003;348:1603-1604.

68. First Consulting Group. Achieving tangible IT benefits in small physician practices. California Health Foundation; 2002. Available at: http: //www.chcf.org/documents/ihealth/AchievingITBenefits.pdf. Accessed May 5, 2003.

69. American Academy of Family Physicians Research and Information Services Division. 2002 FACTS about family practice. Available at: http://www.aafp.org/x530.xml. Accessed May 5, 2003.

70. Greiner A, Knebel E. Institute of Medicine. Committee on the Health Professions Education Summit. Health Professions Education: A Bridge to Quality. Washington, DC: National Academy Press; 2003.
71. American Academy of Family Physicians. Division of Medical Education. 2003 match results and information. 2003 MATCH information sheet. Available at: http://www.aafp.org/match.

72. ACGME Outcome Project [Accreditation Council for Graduate Medical Education Web site]. Available at: http://www.acgme.org/outcome. Accessed June 30, 2003.

73. Davis DA, Barnes B, Fox RD. American Medical Association. The Continuing Professional Development of Physicians: From Research to Practice. Chicago, Ill: AMA Press; 2003.

74. Knowles MS. The Modern Practice of Adult Education: From Pedagogy to Andragogy. Rev ed. Wilton, Conn: Association Press; 1980.

75. Knox AB. Adult Development and Learning. San Francisco, Calif: Jossey-Bass; 1977

76. Merriam SB, Caffarella RS. Learning in Adulthood: A Comprehensive Guide. 2nd ed. San Francisco, Calif: Jossey-Bass; 1999.

77. Levinson DJ. Toward a conception of the adult life course. In: Smelser NJ, ed. Themes of Work and Love in Adulthood. Cambridge, Mass: Harvard University Press; 1980.

78. Fox RD. Continuing professional education. In: Guthrie JW, ed. Encyclopedia of Education. 2nd ed. New York, NY: Macmillan Reference USA; 2003.

79. Alazri MH, Neal RD. The association between satisfaction with services provided in primary care and outcomes in Type 2 diabetes mellitus. Diabet Med. 2003; 20:486-490.

80. Macinko J, Starfield B, Shi L. The contribution of primary care systems to health outcomes within Organization for Economic Cooperation and Development (OECD) countries, 1970-1998. Health Serv Res. 2003:38:831-865

81. Shi L. Primary care, specialty care, and life chances. Int J Health Serv. $1994 ; 24: 431-458$

82. Shi L, Starfield B, Kennedy B, Kawachi I. Income inequality, primary care, and health indicators. J Fam Pract. 1999;48:275-284.

83. Halvorsen JG. Family medicine's failures: reflections on Keystone III. Fam Med. 2001;33:382-387 